\title{
Screening for HIV and linkage to care in adolescents: insights from a systematic review of recent interventions in high- versus low- and middle-income settings
}

This article was published in the following Dove Press journal:

Adolescent Health, Medicine and Therapeutics

\author{
Brian C Zanoni ${ }^{1,2}$ \\ Ryan J Elliott ${ }^{3}$ \\ Anne M Neilan ${ }^{1,2}$ \\ Jessica E Haberer ${ }^{1,2}$ \\ 'Department of Global Health, \\ Massachusetts General Hospital, \\ Boston, MA, USA; ${ }^{2}$ Department of \\ Medicine, Harvard Medical School, \\ Boston, MA, USA; ${ }^{3}$ Premedical \\ Program, Harvard Extension School, \\ Cambridge, MA, USA
}

Introduction: Compared to adults, adolescents and young adults have a higher incidence of HIV infection, yet lower rates of HIV testing. Few evidence-based interventions effectively diagnose new HIV infections among adolescents while successfully providing linkage to care. Methods: We conducted a systematic review of recent interventions to increase HIV testing among adolescents and young adults using data retrieved from PubMed and Google Scholar, and using abstracts presented at the International AIDS Society conferences and Conference on Retroviruses and Opportunistic Infections published between January 1, 2015, and April 28, 2018. Results: We identified 36 interventions ( $\mathrm{N}=14$ in high- income countries and $\mathrm{N}=22$ in low- and middle-income countries) that were published in the literature $(\mathrm{N}=28)$ or presented at conferences $(\mathrm{N}=8)$. Interventions were categorized as behavioral/educational, alternate venue/self-testing, youth-friendly services, technology/mobile health, incentives, or peer-based/community-based interventions. The studies consisted of randomized controlled trials (RCTs), prospective and retrospective observational studies, and quasi-experimental/pre-post evaluations with variable sample sizes. Study designs, populations, and settings varied. All categories showed some degree of acceptability, yet not all interventions were effective in increasing HIV testing. Effectiveness was seen in more than one RCT involving technology/mobile health (2/3 RCTs) and alternative venue/self-testing ( $3 / 3 \mathrm{RCTs}$ ) interventions, and only in one RCT each for behavioral interventions, community interventions, and incentives. There were no effective RCTs for adolescent-friendly services. Data were limited on the number of new infections identified and on the methods to increase linkage to care after diagnosis.

Conclusion: Future studies should include combinations of proven methods for engaging adolescents in HIV testing, while ensuring effective methods of linkage to care.

Keywords: adolescent, HIV, testing, interventions, barriers

\section{Introduction}

Worldwide in 2016, an estimated 2.1 million adolescents aged 10-19 years were living with HIV. ${ }^{1}$ Globally, one-third of all new HIV infections occurs among adolescents. ${ }^{2}$ Eighty percent of all adolescent HIV infections worldwide occur in sub-Saharan Africa where females are disproportionately affected compared to males. ${ }^{1,3}$ In sub-Saharan Africa, less than a third of all adolescents have ever tested for HIV and only $20 \%$ of adolescent girls who are living with HIV know their HIV status. ${ }^{1,3}$ There are limited evidence-based interventions targeting this population that effectively diagnose and link adolescents and young adults to care.
Correspondence: Brian C Zanoni Massachusetts General Hospital, Infectious Diseases, 55 Fruit Street, Cox Building 5th Floor, Boston, MA 02II4, USA

Tel +I 6177248597

Email bzanoni@mgh.harvard.edu 
In the US, more than 61,000 adolescents are living with $\mathrm{HIV}^{4}$ In 2016, of all the new HIV diagnoses among adolescents in the US, $81 \%$ were attributed to male-to-male sexual contact. ${ }^{4}$ Despite the Centers for Disease Control and Prevention (CDC) recommendations for one-time HIV testing for all individuals aged 13-64 and annual testing in high-risk groups, testing rates among adolescents and young adults remain low. ${ }^{4,5}$ Among high school aged men who have sex with men (MSM), only $21 \%$ ever had an HIV test. ${ }^{4}$ Despite numerous interventions to increase HIV testing among high-risk adolescents and young adults, $44 \%$ of those living with HIV have not been tested and are unaware of their positive status. ${ }^{4}$

The Joint United Nations Programme on HIV and AIDS has set the target of 90-90-90 by the year 2020, describing the percentage goals for HIV testing, antiretroviral therapy (ART) initiation, and viral suppression, respectively. ${ }^{1}$ In addition, the WHO has recommended moving to a treatment for all strategy to increase the number of individuals living with HIV who receive ART regardless of CD4 cell count or clinical stage. ${ }^{6}$ Worldwide, adolescents are falling well short of the targeted testing, ART initiation, and viral suppression goals. In the care continuum, estimates of viral suppression among all adolescents living with HIV are $<10 \%{ }^{7,8}$ The largest drop off in the continuum of care for adolescents is in HIV testing and linkage to care where only $41 \%$ know their diagnosis. ${ }^{4,8}$ The ultimate goal of HIV testing is diagnosing new infections, linking individuals to care, and achieving viral suppression; yet there are significant gaps in evidence-based interventions to improve HIV testing and linkage to care for adolescents.

Adolescents face numerous barriers to HIV testing as indicated in Table 1. One of the most common psychological barriers to HIV testing among adolescents is lack of perceived risk. ${ }^{9,10}$ Other psychological barriers include fear of consequences of a positive test, worries about discrimination and rejection, stigma about HIV, sexual orientation, or gender identity. ${ }^{911-17}$ In addition, there are structural barriers to HIV testing among adolescents including never being offered an HIV test, inconvenient hours, lack of insurance, and parental consent. ${ }^{10,16,18-21}$ Mistrust of the health care system and perception of poor attitudes of health care providers also hinder HIV testing for adolescents. ${ }^{11}$ Social factors such as socioeconomic status, gender, and race can also impede HIV testing in adolescents. Interventions to improve HIV testing among adolescents should target these barriers to increase HIV testing and linkage to care.

Improving HIV testing and linkage to care is now recognized as a global health priority, and as a result, several interventions have been developed specifically targeting
Table I Barriers to HIV testing for adolescents

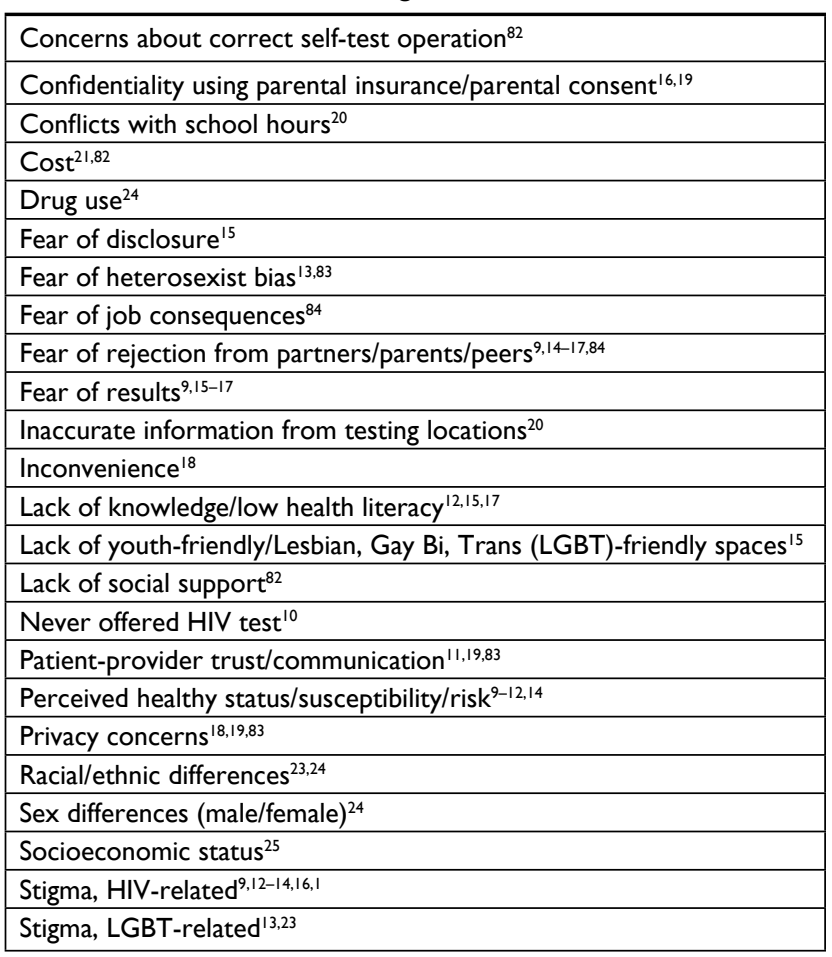

HIV testing uptake among adolescents..$^{22}$ We conducted a systematic review of interventions published between 2015 and 2018 targeting HIV testing among adolescents to highlight the lack of evidence-based, successful interventions that find new HIV infections among adolescents and successfully link them to care. ${ }^{23-25}$

\section{Methods}

We performed a systematic review of HIV testing interventions targeting adolescents that were published between January 2015 and April 28, 2018. We adhered to the Preferred Reporting Items for Systematic Reviews and Meta-Analyses (PRISMA) guidelines. ${ }^{26} \mathrm{We}$ initially searched peer-reviewed journals written in English that were located in PubMed and Google Scholar and published after 2010. We then narrowed our results to those published on or after January 1, 2015. Our target population was adolescents and young adults aged 10-24 years. However, we included studies that included individuals outside of this age range provided that the intervention was targeted toward adolescents and young adults. Keywords searched included HIV, testing, and at least one of the following age terms: adolescent, adolescence, teen, youth, or young adults.

In addition, we searched for abstracts presented at the International AIDS Society Conference (IAS) and at the Conference on Retroviruses and Opportunistic Infections 
(CROI). We were able to search 2015-2018 CROI abstracts, but only 2015-2016 IAS abstracts were available online. Keywords searched included HIV and testing. Abstracts were then screened for at least one of the following age terms: adolescent, adolescence, teen, youth, or young adults.

Potential journal articles were uploaded into Covidence, a non-profit website working with the Cochrane database to improve systematic reviews. (www.covidence.org, Melbourne, Australia) Duplicates were removed. After initial screening of the title and abstract, two authors (BCZ and RJE) independently reviewed potential studies. Conflicts were resolved by reviewing the full text article and discussing inclusion/exclusion criteria. We excluded review articles, studies that did not include an intervention, that did not report primary data for HIV testing, or that were targeting children or adults outside our specified age range of 10-24 years. We then extracted data from the full text articles included in this review.
We used the PRISMA guidelines in assessing the strength of evidence and bias for clinical trials and evaluated random sequence generation, allocation concealment, blinding, and outcome reporting. ${ }^{27}$ Randomized controlled trials (RCTs) were considered less biased than pre-post evaluations, and prospective and retrospective observational studies. Interventions that were evaluated and published in peer reviewed journals were considered less biased than abstracts from conference proceedings that could only be judged by study design. Observational studies were evaluated for bias using the GRADE guidelines and included an assessment of eligibility, controls, loss to follow-up, and outcome consistency. ${ }^{28}$

\section{Results}

\section{Description of studies identified}

Search results included 4,700 potential articles as indicated in the PRISMA flow-diagram in Figure 1. We excluded 85 duplicates,

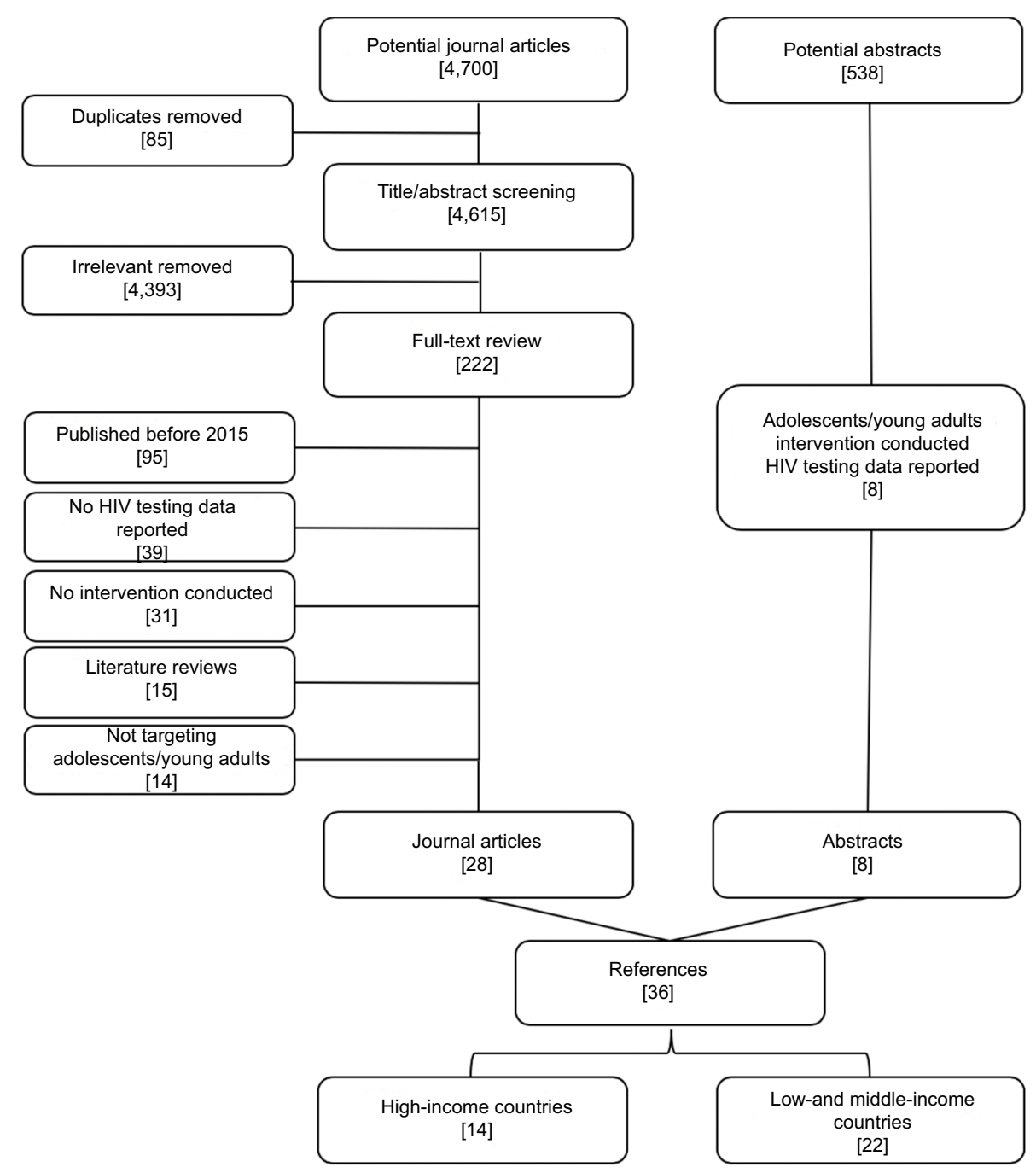

Figure I PRISMA figure of inclusion/exclusion criteria. 
as well as 4,393 studies that were not relevant to adolescent HIV testing interventions. We reviewed 222 studies for eligibility based on the above criteria and excluded 194 of them: 95 were published between 2010 and 2014; 39 did not report primary data for HIV testing; 31 did not include an intervention involving adolescent HIV testing; 15 were literature reviews; and 14 were not targeting adolescents. We included 28 articles in our final review. In addition, among the 546 IAS and 292 CROI abstracts, 7 and 1 met our inclusion criteria, respectively. None of these were subsequently published in the literature.

We identified a total of 36 studies for this analysis. We separated the studies into those conducted in high-income countries (a total of 14 studies) and those conducted in low- and middle-income countries (a total of 22 studies) and arranged them by the type of intervention as indicated in Table 2. All of the studies from high-income countries took place in the US $(\mathrm{N}=14)^{16,29-41}$ and will be referred to as US from here forward. The low- and middle-income countries included South Africa $(\mathrm{N}=6),{ }^{42-47}$ Kenya $(\mathrm{N}=4),{ }^{48-51}$ Bangladesh $(\mathrm{N}=2),{ }^{52,53}$ Zambia $(\mathrm{N}=2),{ }^{45,54}$ Liberia $(\mathrm{N}=1),{ }^{55}$ Ethiopia $(\mathrm{N}=1),{ }^{56}$ Malawi $(\mathrm{N}=1),{ }^{57}$ Mozambique $(\mathrm{N}=1),{ }^{58}$ Myanmar $(\mathrm{N}=1),{ }^{59}$ Ghana $(\mathrm{N}=1),{ }^{60}$ Indonesia $(\mathrm{N}=1),{ }^{61}$ Zimbabwe $(\mathrm{N}=1),{ }^{62}$ Uganda $(\mathrm{N}=1),{ }^{48}$ and Haiti $(\mathrm{N}=1)^{63}$ with two studies taking place in more than one country. ${ }^{45,48}$ The interventions were organized into six categories as defined in Table 3. The interventions to increase HIV testing among adolescents and young adults consisted of behavioral/educational interventions $(\mathrm{N}=4)^{29,30,55,56}$, alternate venue/self-testing $(\mathrm{N}=11),{ }^{31-34,42-45,50,57,58}$ youth-friendly services $(\mathrm{N}=2),{ }^{59,60}$ technology/mobile health $(\mathrm{N}=9),{ }^{16,35-39,49,51,61}$ incentives $(\mathrm{N}=3),{ }^{53,54,62}$ and peer/community-based interventions $(\mathrm{N}=7){ }^{40,41,46-48,52,63}$ The median sample size was 613 individuals (inter-quartile range $=261-2,169$ ). The types of studies included RCTs ( $\mathrm{N}=13)$, 29,31,36,38,39,42,45,47,49,51,55,60,62 observational studies $(\mathrm{N}=15),{ }^{16,32-35,41,44,58,61}$ and quasi-experimental/pre-post evaluations $(\mathrm{N}=8) \cdot{ }^{30,37,40,46,52,54,56,59}$

Among the studies in the US, three studies contained information on new HIV diagnoses (ranging from $0.6 \%$ to $11.3 \%$ with a median of $3.2 \%) .{ }^{32,34,41}$ All contained information on linkage to care (ranging from $85 \%$ to $100 \%$ ). In low- and middle-income countries, nine studies included information on new HIV infections (ranging from $0.6 \%$ to $9.4 \%$ with a median of $3.4 \%))^{3,43-45,48,50,53,56,57}$ Of these, three included information on the number linked to care (ranging from $50 \%$ to $100 \%$ with an absolute of $97 \%$ [94/97]). ${ }^{53,57,63}$

\section{Bias assessment}

Of the 36 studies included in our review, 13 were RCTs and 23 were observational studies. ${ }^{16,30,32-35,37,40,41,44,46,52,54,56,58,59,61}$
Three of the RCTs $\mathrm{s}^{39,42,62}$ and five of the observational studies $^{43,44,52,54,61}$ were presented in abstracts; these studies were excluded from the risk of bias assessment due to insufficient information. Five of the remaining observational studies were pre-post evaluations of an intervention.

Of the remaining ten $\mathrm{RCTs}$, both random sequence generation and allocation concealment were discernible for four studies from their study methods. ${ }^{36,51,55,60}$ Two studies reported random sequence generation only. ${ }^{31,38}$ Four RCTs did not report either random sequence generation or allocation concealment. ${ }^{29,45,47,49}$ Given the nature of the interventions, blinding of participants and personnel was rarely possible and was reported in only one $\mathrm{RCT} \mathrm{T}^{38}$ In that study, only participants were blinded to arm allocation and blinding of outcome assessors was not reported. All RCTs report HIV testing outcomes as predefined primary or secondary outcomes.

All of the remaining 17 observational studies reported eligibility criteria that were applied consistently for all participants. Only one observational study included a control group. ${ }^{59}$ Four observational studies reported loss to followup data. ${ }^{16,30,40,56}$ Loss to follow-up rates ranged from $16 \%$ to $43 \%$. Implementation challenges were noted for higher loss to follow-up rates. ${ }^{40,56}$

\section{Interventions}

Below we report summaries of the individual interventions designed to increase HIV testing among adolescents separated by intervention category (behavioral/educational, alternative venue/self-testing, technology/mobile health, incentives, youth-friendly services, or peer/community) and country category (high-income versus low- and middle-income countries). Within each intervention category, interventions are listed beginning with the least biased (ie, RCTs followed by pre-post evaluations and observational studies). Interventions published in only abstract form are reported last.

\section{Behavioral/educational interventions $(\mathrm{N}=4)$}

There were two interventions from the US that provided a combination of educational material and behavioral interventions targeting adolescents interacting with the criminal justice system ${ }^{29,30}$ with one RCT. ${ }^{29}$ Letourneau et al randomized 105 adolescents attending juvenile drug court to receive standard care compared to risk reduction therapy. ${ }^{29}$ The intervention involved adolescent-parent dyads in 24 weekly, 60-90 minute sessions involving cognitive behavior therapy and behavior management training with contingency-contracting with a point earning system. At the end of the study, there 


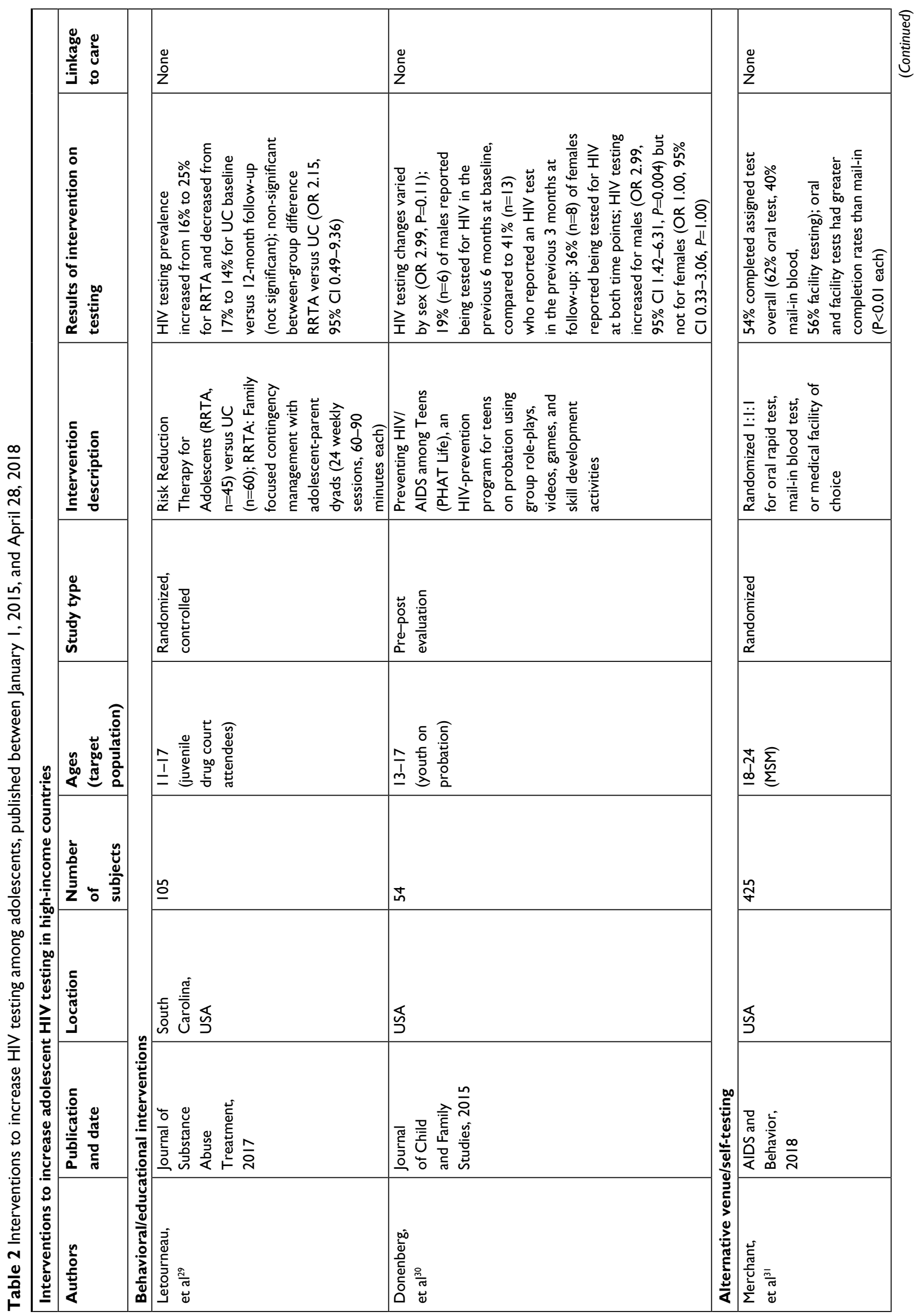




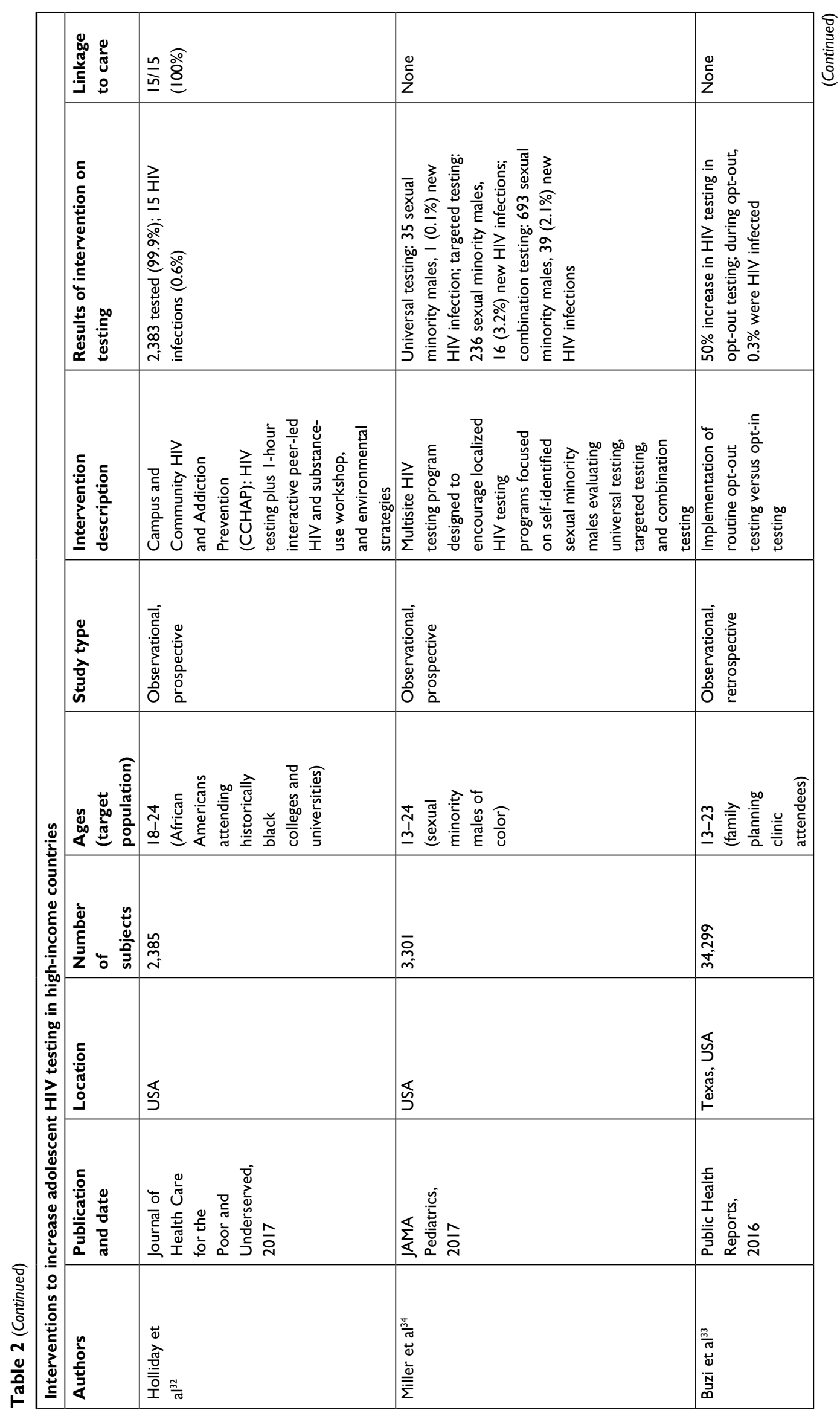




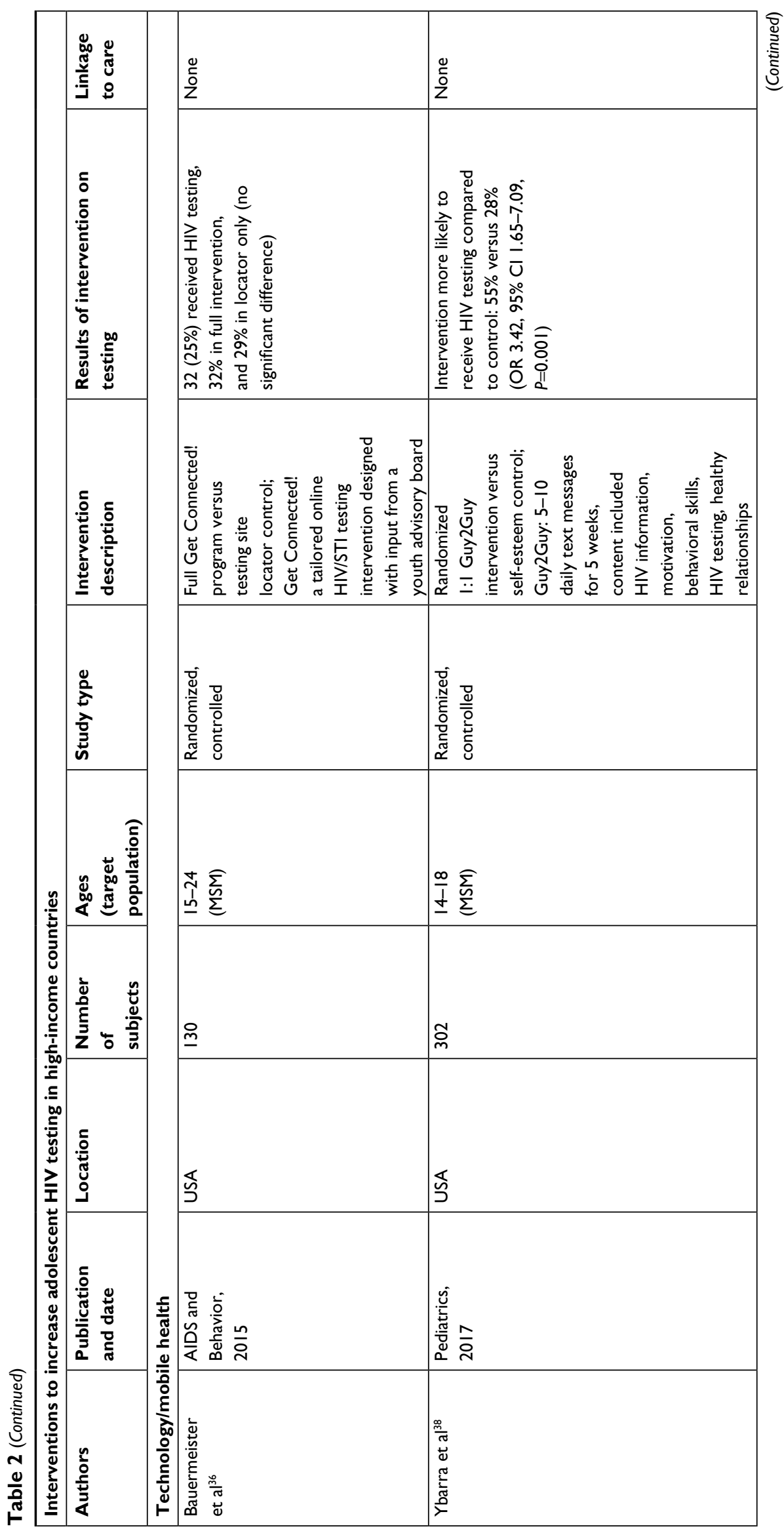




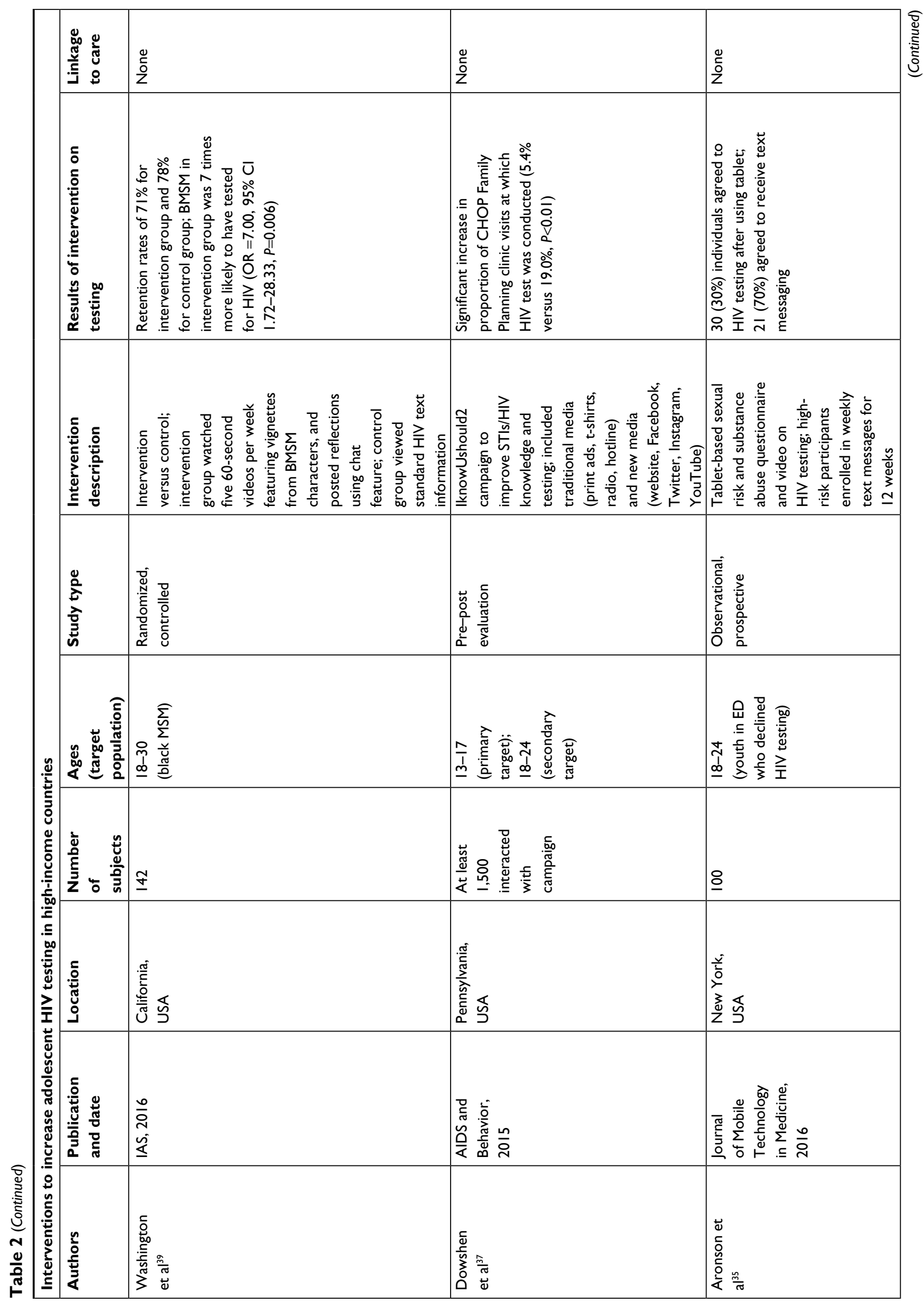




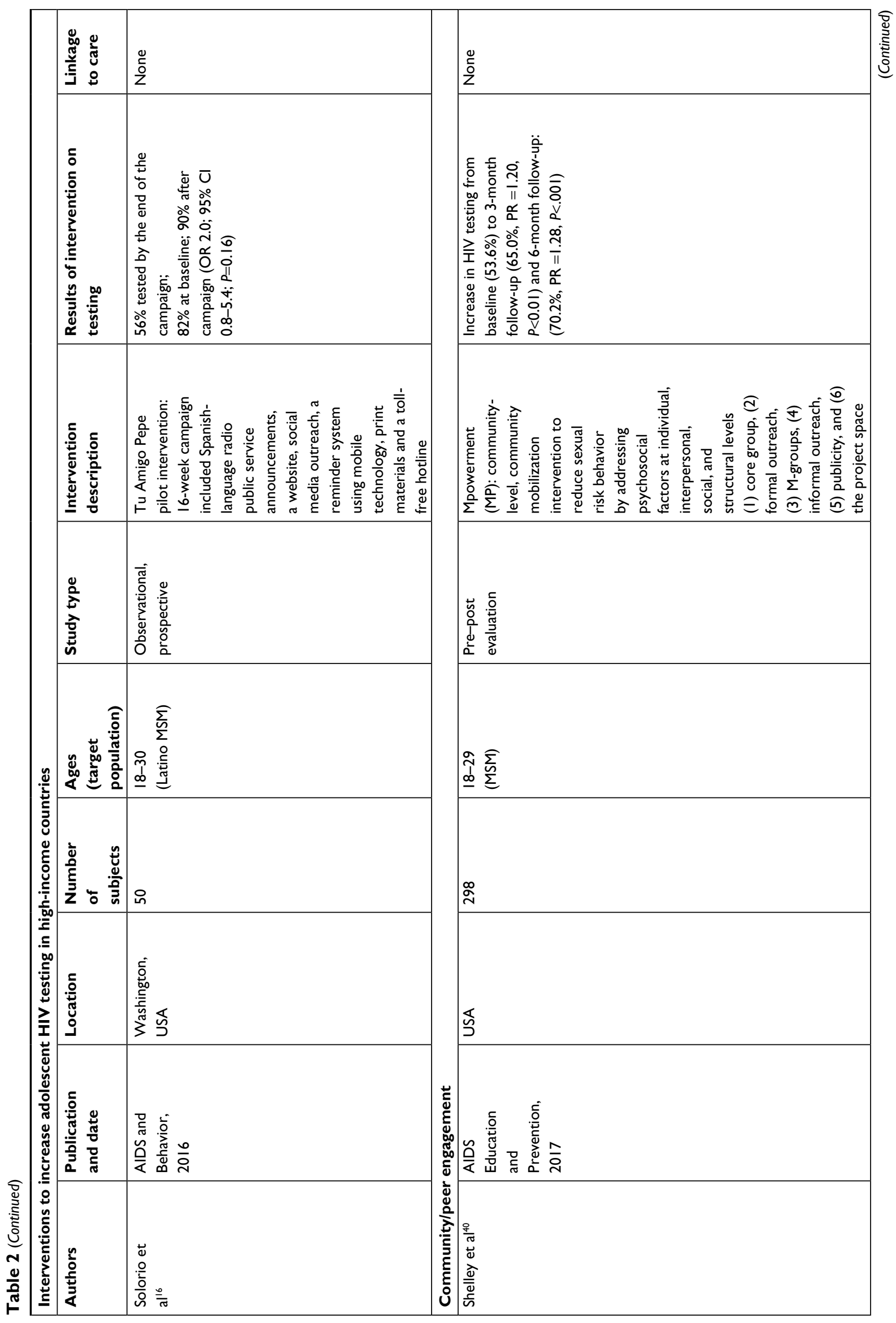




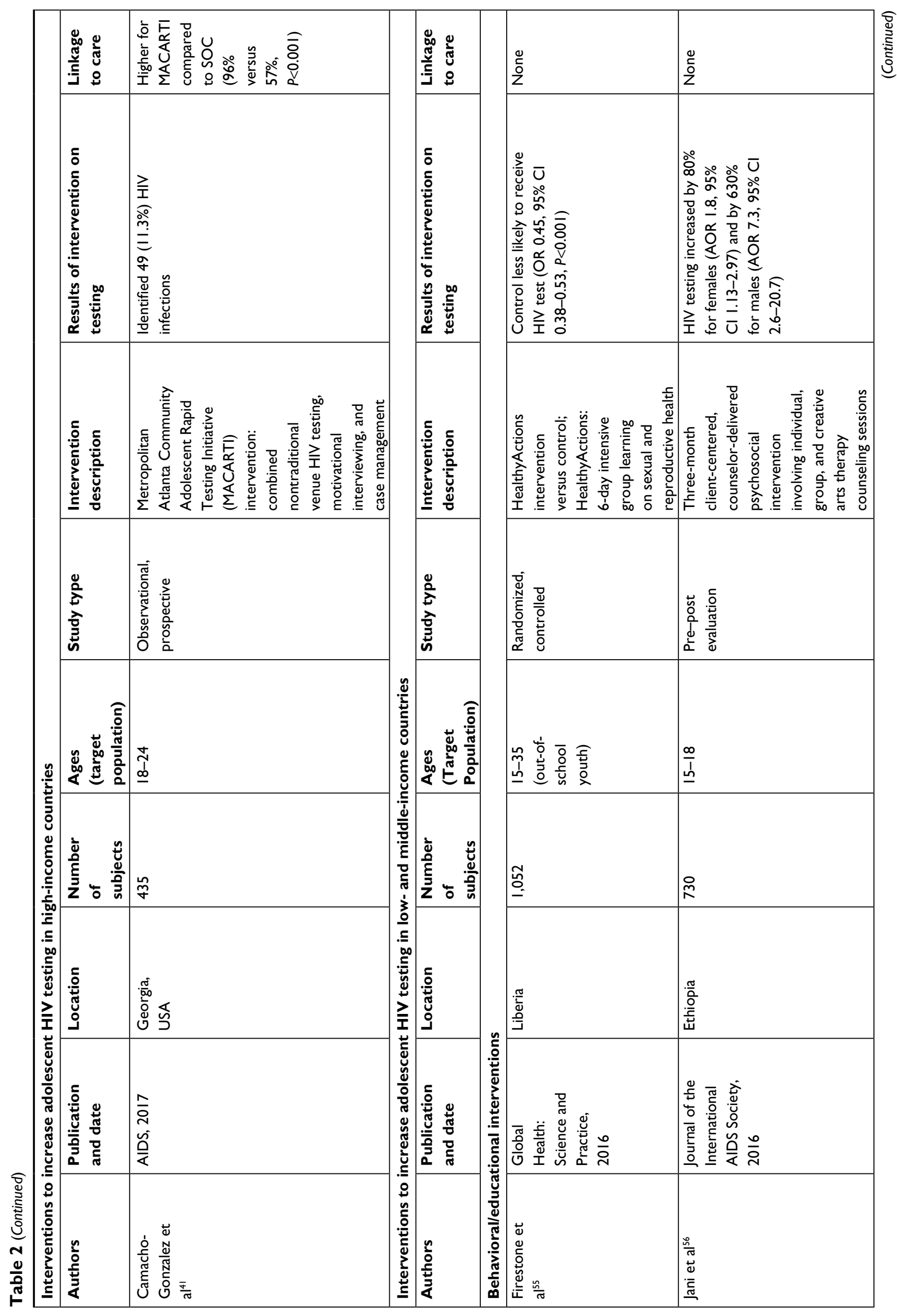




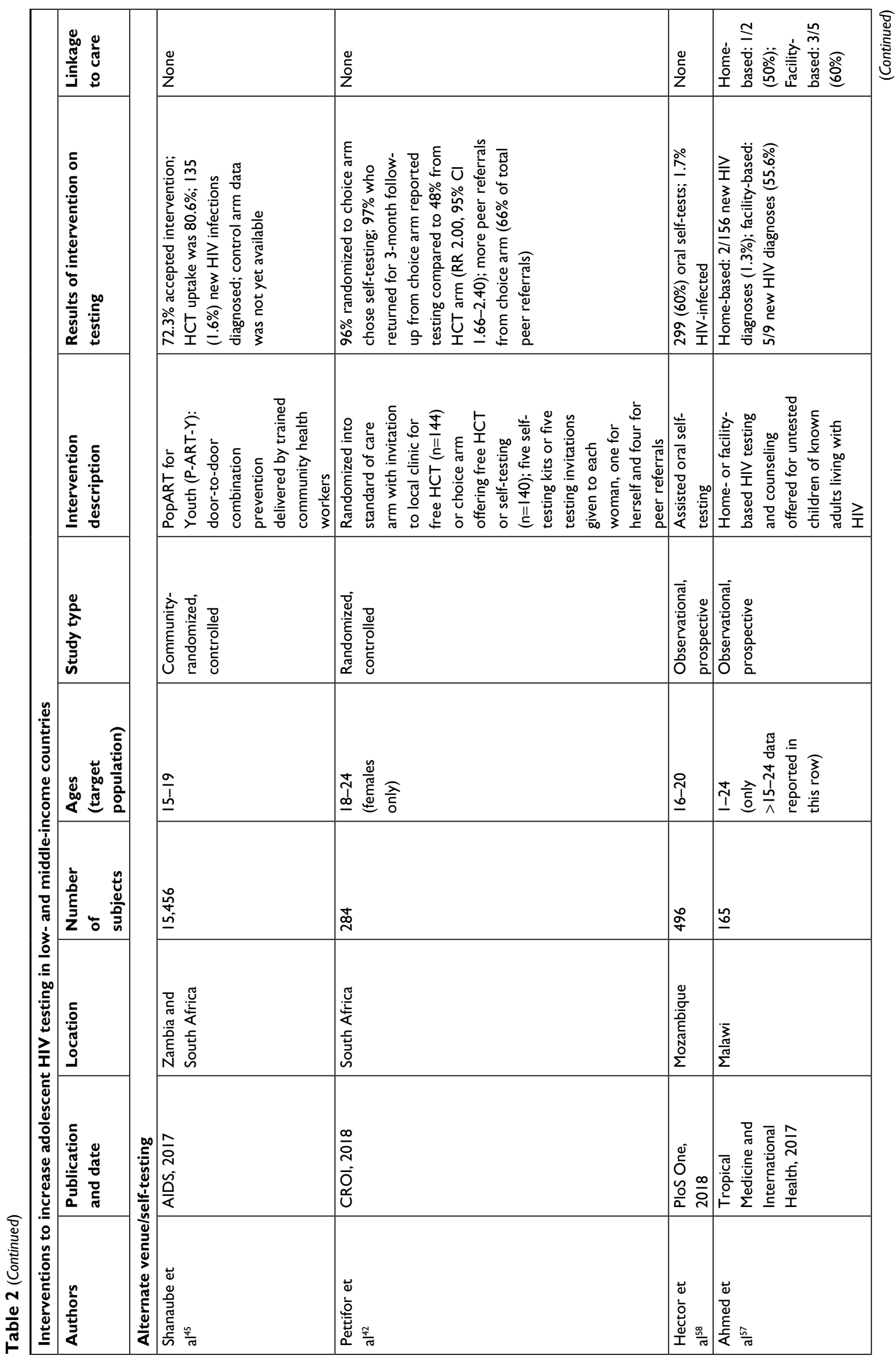




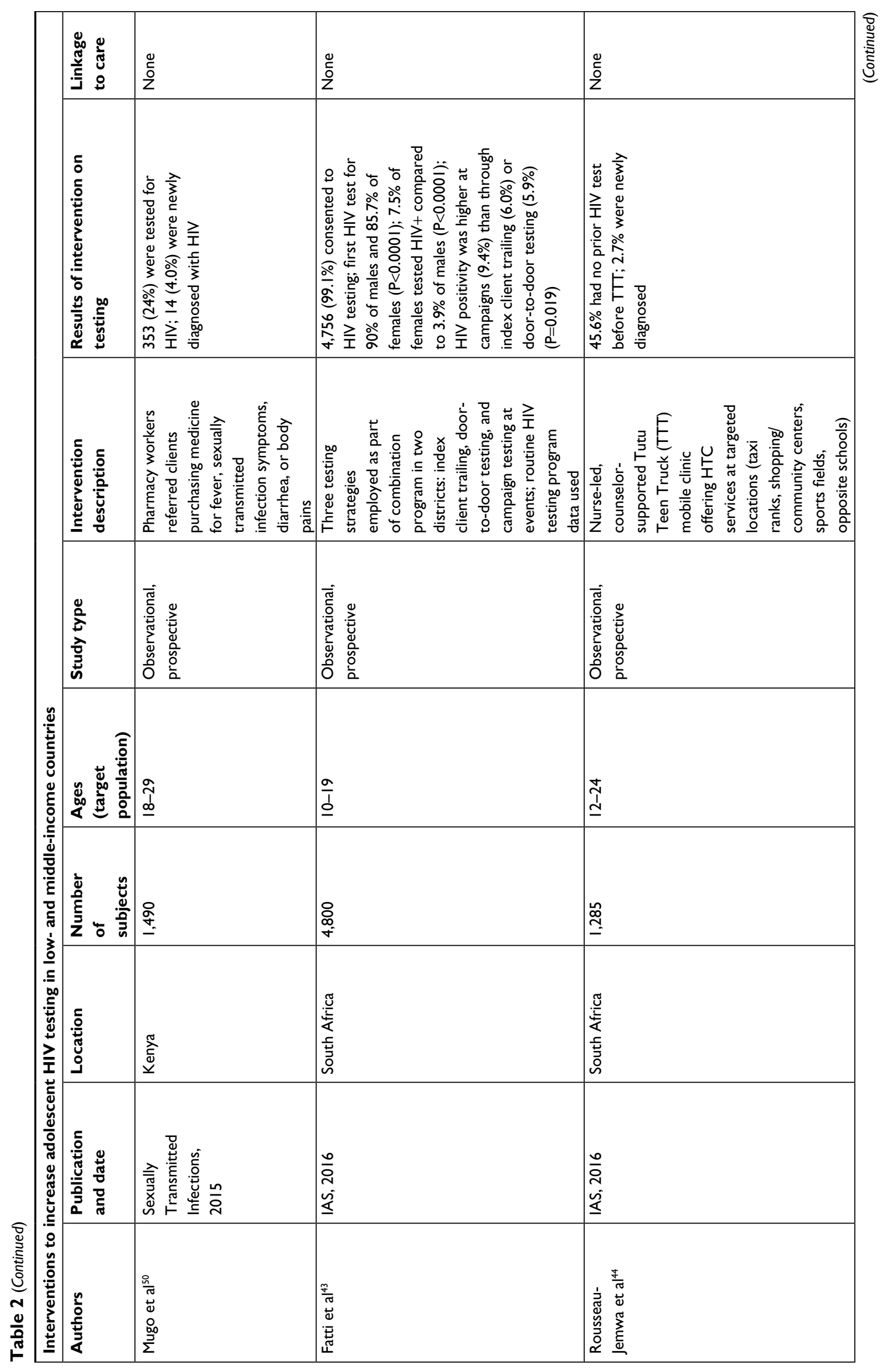




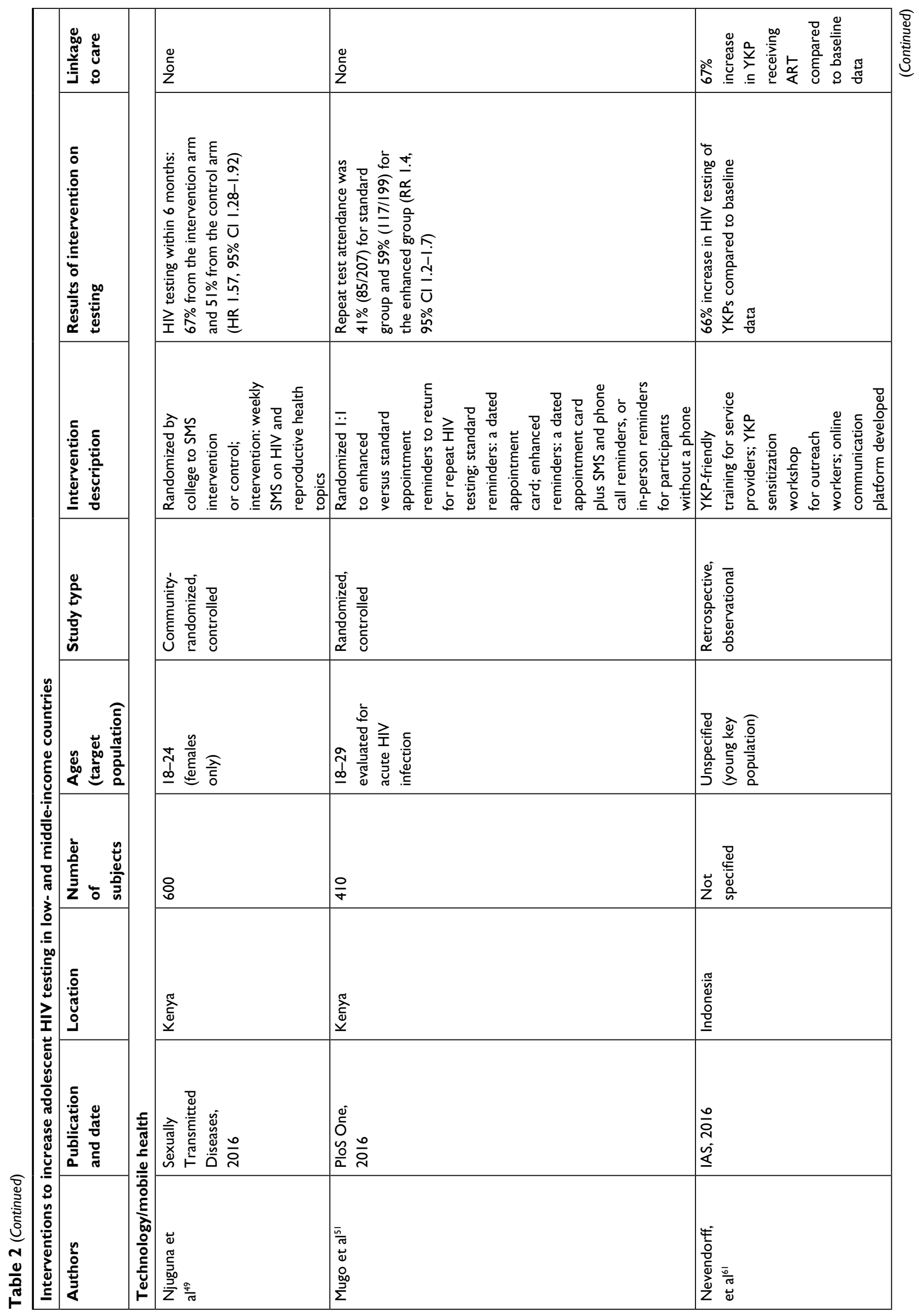




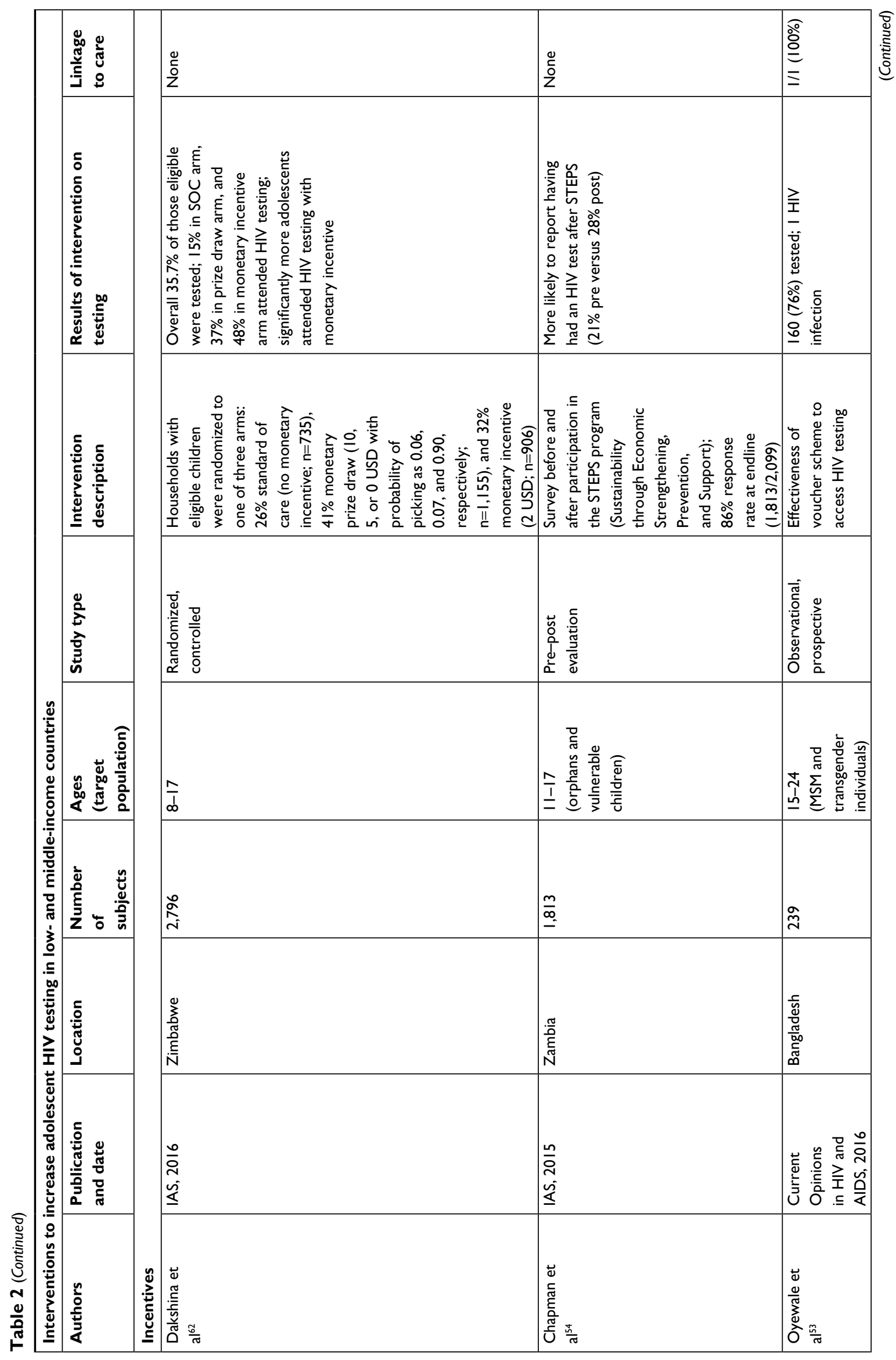




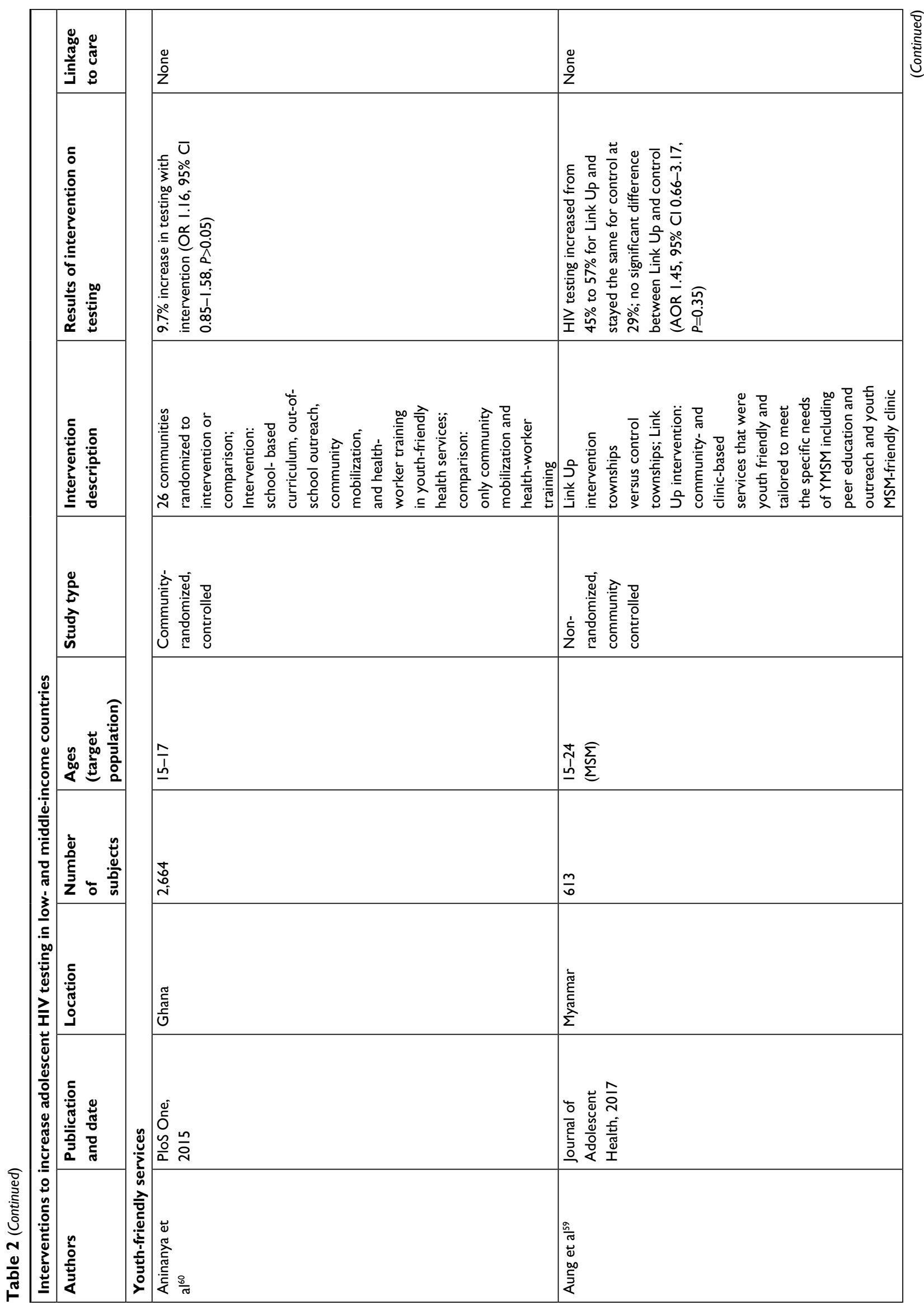




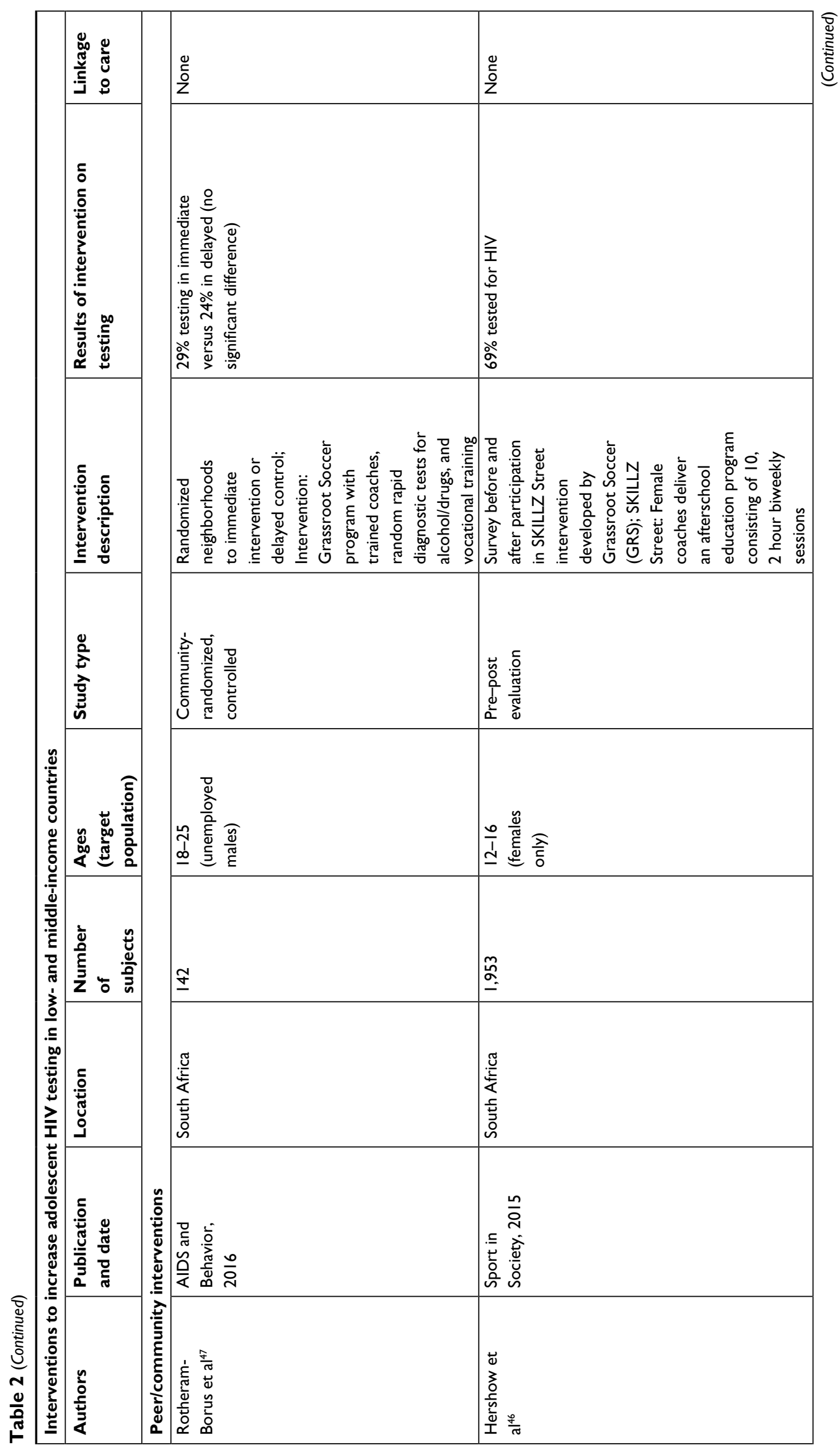




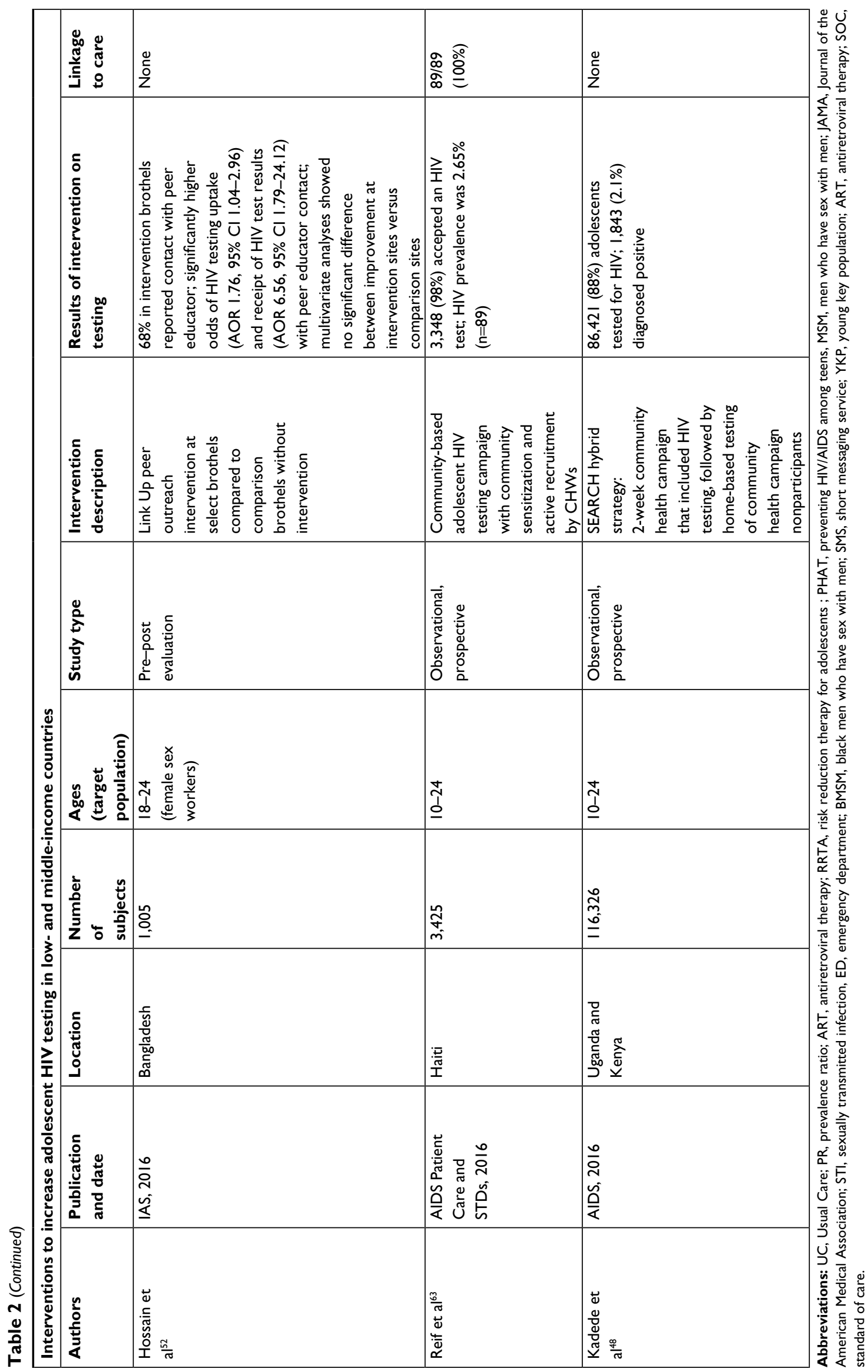


Table 3 Categories of HIV testing interventions

\begin{tabular}{|l|l|l|}
\hline Category & Definition & Examples \\
\hline $\begin{array}{l}\text { Behavioral/ } \\
\text { educational }\end{array}$ & $\begin{array}{l}\text { Interventions that provided information on } \\
\text { HIV and/or focused on behavioral change }\end{array}$ & $\begin{array}{l}\text { Cognitive behavior therapy } \\
\text { - Behavior management training }\end{array}$ \\
\hline $\begin{array}{l}\text { Alternative } \\
\text { venue/self-testing }\end{array}$ & $\begin{array}{l}\text { Interventions that provided HIV counseling } \\
\text { and testing outside of traditional health care } \\
\text { facilities }\end{array}$ & $\begin{array}{l}\text { - Mobile testing vans } \\
\text { In-home testing } \\
\text { - Oral, home self-testing }\end{array}$ \\
\hline $\begin{array}{l}\text { Technology/ } \\
\text { mobile health }\end{array}$ & $\begin{array}{l}\text { Interventions using social media, internet, or } \\
\text { mobile phones }\end{array}$ & $\begin{array}{l}\text { - Text messaging } \\
\text { Ondine chat groups }\end{array}$ \\
\hline Incentives & $\begin{array}{l}\text { Interventions that provided monetary or } \\
\text { coupon reimbursement for HIV testing }\end{array}$ & - Cash \\
\hline $\begin{array}{l}\text { Youth-friendly } \\
\text { services }\end{array}$ & $\begin{array}{l}\text { Interventions that focused explicitly on } \\
\text { targeting services for an adolescent population }\end{array}$ & $\begin{array}{l}\text { Prize draw } \\
\text { Pealth-worker training }\end{array}$ \\
\hline Peer/community & $\begin{array}{l}\text { Interventions that used interactions with } \\
\text { trained community members, peers, or groups }\end{array}$ & $\begin{array}{l}\text { Youth-friendly facilities } \\
\text { Youth soccer programs }\end{array}$ \\
\hline
\end{tabular}

was no difference in HIV testing in the intervention group (25\%) compared to those in standard care (14\%) $(95 \%$ CI 0.49-9.36). This RCT did not report random sequence generation, allocation concealment, or blinding.

In an uncontrolled observational study, Donenberg et al enrolled 54 adolescents aged 13-17 years who had been arrested into the program Preventing HIV/AIDS among Teens (PHAT life), which used group format role plays, videos, and games as an HIV prevention program. ${ }^{30}$ There was no change in HIV testing among females, while there was a significant increase in testing from $19 \%$ at baseline to $41 \%(P=0.004)$ at the end of the intervention for males. Both programs were labor intensive, required multiple visits over time and did not significantly increase HIV testing for the defined populations at the end of the program nor did they report the number of new HIV infections diagnosed.

In low- and middle-income countries, two studies provided educational materials and behavioral interventions ${ }^{55,56}$ with one RCT. ${ }^{55}$ In Liberia, 1,052 out-of-school adolescents and young adults aged 15-35 years were randomized to receive standard care versus HealthyActions, a 6-day intensive group learning on sexual and reproductive health. ${ }^{55} \mathrm{At}$ the completion of the study, participants in the control group (42\%) were less likely to undergo HIV testing (OR 0.45; $95 \%$ CI $0.38-0.53 ; P<0.001)$ than the intervention group $(88 \%)$. This RCT included both random sequence generation and allocation concealment but was not blinded.

A separate non-controlled observational study in Ethiopia enrolled 730 adolescents aged 15-18 years in a 3-month client-centered, counselor-delivered psychosocial intervention that involved individual, group, and creative arts therapy counseling sessions. ${ }^{56}$ At the end of the study, both females (AOR 1.8; 95\% CI 1.13-2.97) and males (AOR 7.3; 95\%
CI 2.6-20.7) were more likely to have received an HIV test compared to before enrollment. The authors did not report on the number who tested positive or linkage to care. Both of these interventions were labor and training intensive and required multiple visits over time.

\section{Alternate venues/self-testing $(\mathrm{N}=\mathrm{II})$}

In the US, there were four studies involving alternative venue testing strategies for adolescents ${ }^{31-34}$ with only one RCT. ${ }^{31}$ Merchant et al randomized 425 MSM aged 18-24 to perform an oral rapid self-test, self-mail in blood test, or testing at a local medical facility. ${ }^{31}$ Of those enrolled, only $54 \%$ completed their assigned test. Oral self-testing (62\%) and facility-based testing (56\%) were superior $(P<0.01$ each) to mail in blood testing (40\%). This RCT reported random sequence generation but did not report allocation concealment or blinding nor did they report the number of HIV diagnoses or linkage to care.

The alternative strategies investigated by the non-RCT studies included testing on campus at historically black colleges and universities, ${ }^{32}$ opt-out testing at family planning clinics, ${ }^{33}$ and targeted testing tailored to sexual minority men. ${ }^{34}$ All of these strategies reported increased HIV testing among adolescents. An observational study evaluating the provision of HIV testing on campus among 2,385 students attending historically black colleges and universities over a 2 -year period detected new HIV infections in $0.6 \%$ of those tested. ${ }^{32}$ The investigators were able to link $100 \%(\mathrm{~N}=15)$ of individuals newly diagnosed with HIV to care. A separate observational study of 3,301 sexual minority men of color aged 13-24 found that targeted testing detected the highest number of new HIV infections (6.3\%) compared to universal testing $(0.1 \%)$ and combination of universal and targeted test- 
ing $(5.6 \%))^{34}$ This study was not controlled or blinded, and did not report on loss to follow-up. A retrospective analysis evaluated the historical effect of opt-out testing compared to opt-in testing among 34,299 individuals aged 13-23 years attending family planning clinics. ${ }^{33}$ They found a $50 \%$ increase in HIV testing during the opt-out period with $0.3 \%$ new HIV diagnoses.

In low- and middle-income countries, there were seven studies evaluating alternative HIV testing strategies ${ }^{42-45,50,57,58}$ with two RCTs. ${ }^{42,45}$ A community RCT in Zambia and South Africa involving 15,456 adolescents aged 15-19 years found that door-to-door testing had high uptake (81\%) with $1.6 \%$ of those tested newly diagnosed with HIV. ${ }^{45}$ This RCT did not include random sequence generation, allocation concealment, or blinding. In South Africa, an RCT involving 284 females aged 18-24 years showed that home-based self-testing had higher uptake (97\%) than referrals to local clinic (48\%) (RR 2.00, 95\% CI 1.66-2.40). ${ }^{42}$ This study was reported in abstract form.

There were five non-RCT studies that evaluated alternative venue HIV testing among adolescents. ${ }^{43,44,50,57,58}$ In an observational study of 496 individuals aged 16-20 years from Mozambique, uptake of oral self-testing was $60 \%$ with $1.7 \%$ newly diagnosed with HIV. ${ }^{58}$ A prospective, observational study of 165 adolescents aged 15-24 years in Malawi evaluated untested adolescents with known HIV-infected adult family members by use of household testing and found $9.7 \%$ new HIV infections with $77 \%$ successfully linking to care. ${ }^{57}$ A prospective, observational study offering HIV testing to 1,490 symptomatic youth aged 18-29 years presenting to pharmacies in Kenya found low uptake for testing (24\%); however, of those tested, $4 \%$ were newly diagnosed with HIV. ${ }^{50}$ A prospective, observational analysis of 4,800 adolescents in South Africa aged 10-19 years evaluated three testing strategies: index client trailing, door-to-door testing, and campaign testing at events. ${ }^{43}$ In this study, 4,756 (99.1\%) agreed to HIV testing. Diagnosing new HIV infections was highest with testing campaigns $(9.4 \%)$, followed by index client trailing (6.0\%) and door-to-door testing (5.9\%; $P=0.019)$. Another South African observational study that evaluated 1,285 youth aged $12-24$ years utilizing mobile HIV testing trucks specifically targeting adolescents found a high uptake of first-time HIV testers (45.6\%) and found $2.7 \%$ of individuals testing to be newly diagnosed with $\mathrm{HIV}^{44}$

\section{Technology/mobile health $(\mathrm{N}=9)$}

In the US, there were six technology or mobile health interventions ${ }^{16,35-39}$ with three RCTs. ${ }^{36,38,39}$ Ybarra et al randomized
302 MSM aged 14-18 years to receive a self-esteem control versus Guy2Guy program that involved daily text messaging for 5 weeks providing HIV information, motivation and behavioral skills, the importance of HIV testing, and healthy relationships. Individuals randomized to the intervention were more likely to undergo HIV testing (OR 3.42; 95\% CI $1.65-7.09 ; P=0.001) .{ }^{38}$ This RCT included random sequence generation but did not report allocation concealment or blinding. Washington et al randomized 142 black MSM aged 18-30 years old to watch five 60-second videos per week that included vignettes from black MSM characters and to participate in reflections using a group chat feature compared to a control group that received standard information via text messaging. Individuals in the intervention group were more likely to undergo HIV testing compared to the control group (OR 7.0; 95\% CI 1.72-28.33; $P=0.0006) .{ }^{39}$ This RCT was reported in abstract form. Bauermeister et al randomized 130 MSM aged 15-24 years to use of an online HIV site testing locator or Get Connected!, a tailored online HIV/sexually transmitted infection intervention with a website, where the logo and online materials were designed with input from a youth advisory board. ${ }^{36}$ When randomized to the intervention or use of an online testing site locator, there was no statistical difference in HIV testing rates in those receiving the full intervention (32\%) compared to those receiving the testing locator only $(29 \%, P>0.05$ exact not reported). This RCT reported both random sequence generation and allocation concealment. None of these studies reported on the number of new HIV diagnoses or linkage to care.

Among the non-randomized studies in the US evaluating technology, Dowshen et al reported an observational pre/post evaluation of the IknowUshould 2 campaign which used traditional media (print/radio) and technology-based media such as websites, Facebook, Twitter, Instagram, and YouTube to promote HIV testing among 1,500 adolescents who interacted with the campaign. ${ }^{37}$ Over the 9 months of the program, there was a significant increase in visits to a family planning clinic for HIV testing $(5.4 \%-19 \% ; P<0.01)$. This study did not control for temporal differences or other possible confounding factors. Solorio et al reported an observational evaluation of 50 Latino MSM using the Tu Amigo Pepe intervention, a 16-week campaign in the US that included Spanish-language radio announcements, a website, social media outreach, text message reminders, and a toll-free hotline. ${ }^{16}$ The intervention did not significantly increase HIV testing (90\%) from baseline (82\%) (OR 2.0; 95\% CI 0.8-5.4; $P=0.16)$. Neither study reported the number of new HIV infections or linkage to care. Aronson et al conducted a tablet-based intervention 
for 100 young adults aged 18-24 presenting an emergency department who had declined HIV testing. ${ }^{35}$ After the intervention, $30 \%$ of youth tested and $70 \%$ agreed to participate in a 12 -week program of weekly text messages.

In low- and middle-income countries, there were three interventions using technology or mobile health ${ }^{49,51,61}$ including two RCTs. ${ }^{49,51}$ In Kenya, a randomized text messaging trial involving 600 women aged 18-24 found that women in the intervention group were more likely (67\%) to receive HIV testing within 6 months compared to control (51\%) (HR $1.57 ; 95 \%$ CI 1.28-1.92). ${ }^{49}$ This RCT did not include random sequence generation, allocation concealment, or blinding nor did they report the number of new HIV diagnoses. Another RCT in Kenya randomized 410 individuals aged 18-19 years who were evaluated for acute HIV infection to receive appointment reminders via text message compared to enhanced reminders including dated appointment cards, text message reminders, and phone call reminders to increase repeat HIV testing. ${ }^{51}$ Repeat HIV testing was $41 \%$ in the standard group and 59\% in the enhanced group (RR 1.4; 95\% CI 1.2-1.7). This RCT reported both random sequence generation and allocation concealment but did not report the number of new HIV diagnoses.

In a retrospective observational study from Indonesia, a combination intervention that included key-populationfriendly services and outreach with an online communication forum found a $66 \%$ increase in HIV testing compared to baseline and a $67 \%$ increase in those receiving ART compared to baseline. ${ }^{61}$

\section{Incentives $(\mathrm{N}=3)$}

Three studies involved interventions that provided incentives to adolescents for undergoing HIV testing, all of which were conducted in low- and middle-income countries: Bangladesh, ${ }^{53}$ Zambia, ${ }^{54}$ and Zimbabwe ${ }^{62}$ with only one RCT. ${ }^{62}$ Dakshina et al randomized 2,796 individuals aged 8-17 years in Zimbabwe into three arms: standard of care (no incentive) versus a prize draw ( $6 \%$ chance of getting $\$ 10,7 \%$ chance of getting $\$ 5$, and $90 \%$ of getting $\$ 0$ ) versus a guaranteed monetary incentive of $\$ 2 .{ }^{62}$ Overall $35.7 \%$ of individuals were tested: $15 \%$ in the standard of care; $37 \%$ in prize draw; $48 \%$ in monetary incentive. The investigators identified 11 new HIV infections: $4(0.3 \%)$ in the monetary incentive arm, 7 $(0.8 \%)$ in the prize-draw arm, and 0 in the standard of care arm. This RCT was reported in abstract form; therefore, a full bias assessment could not be conducted.

An observational pre/post evaluation in Zambia evaluated 1,813 orphans and vulnerable children aged $11-17$ years who participated in the STEPS program (Sustainability through Economic Strengthening, Prevention and Support). ${ }^{54}$ Individuals enrolled in the program were more likely to have had an HIV test after the program (28\%) compared to prior to the intervention (21\%). The authors did not report the number of infections identified or linkage to care. An observational study in Bangladesh evaluated 239 MSM and transgender individuals aged 15-24 years in using a voucher system to access HIV testing. ${ }^{53}$ Of the vouchers distributed, $160(76 \%)$ were returned for testing and $1(0.6 \%)$ individual was found to be HIV infected and subsequently linked to care.

\section{Youth-friendly services $(\mathrm{N}=2)$}

There were two interventions involving the use of youthfriendly services to improve HIV testing among adolescents, both in low- and middle-income countries: Myanmar ${ }^{59}$ and Ghana ${ }^{60}$ with one RCT. ${ }^{60}$ A community randomized trial in Ghana evaluated 2,664 adolescents aged 15-17 years who participated in youth-friendly health services, school-based curriculum, outreach, and community mobilization with health-worker training in youth-friendly service compared to control with community mobilization and youth-friendly services only. ${ }^{60}$ Compared to the control, adolescents receiving the full curriculum had a 9.7\% increase in HIV testing, which was not statistically significant (OR 1.16; 95\% CI 0.85-1.58). This RCT reported both random sequence generation and allocation concealment.

A non-randomized, controlled study in Myanmar evaluated 613 MSM aged 15-24 years who participated in the Link Up intervention compared to control townships. ${ }^{59}$ The intervention consisted of community and clinic-based youthfriendly services and included peer education, outreach, and a youth-/MSM-friendly clinic. HIV testing increased from $45 \%$ to $57 \%$ in the intervention group and was unchanged at $29 \%$ in the control group (OR 1.45; 95\% CI 0.66-3.17). Neither study reported on the number of new HIV diagnoses during the intervention nor did they discuss linkage to care.

\section{Peer/community interventions $(\mathrm{N}=7)$}

In the US, there were two non-randomized, non-controlled studies that evaluated community interventions to increase HIV testing among adolescents. Mpowerment, a communitylevel mobilization intervention targeting MSM of color aged 18-29 years, found increased testing from $54 \%$ at baseline to $70 \%$ at 6 months $(P<0.001)$, but it did not report the number of newly diagnosed or linked to care. ${ }^{40}$ Metropolitan Atlanta Community Adolescent Rapid Testing Initiative (MACARTI) combined non-traditional venue HIV testing, motivational 
interviewing, and case management targeting youth and identified $11.3 \%$ of testers with new HIV infections, $96 \%$ linked to care compared to $57 \%$ under standard of care $(P<0.001) .{ }^{41}$

In low- and middle-income countries, five studies assessed community- or peer-focused interventions ${ }^{46-48,52,63}$ with one RCT. ${ }^{47}$ A community randomized trial in South Africa evaluated the Grassroot Soccer program that included trained coaches, educational/vocational training, and use of rapid HIV diagnostics. Among the 142 males, the program did not increase HIV testing (29\%) compared with delayed enrollment into the program $(24 \%) .{ }^{47}$ This RCT did not report random sequence generation, allocation concealment, or blinding.

In a separate observational study of the Grassroot Soccer intervention among 1,953 females, $69 \%$ of participants tested for HIV; however, there was no comparison or control group. ${ }^{46}$ Neither study reported on the number of new HIV diagnoses or linkage to care. In Bangladesh, an observational study of the Link Up peer outreach program targeted HIV testing among 1,005 young adult female sex workers working in brothels, but it did not find a significant difference in HIV testing in brothels that had the intervention compared to those that did not participate in the intervention. ${ }^{52}$ In Haiti, an observational evaluation of a community-based adolescent HIV testing campaign tested 3,348 individuals, of whom $98 \%$ offered testing. ${ }^{63}$ They diagnosed $89(2.7 \%)$ new HIV infections, all of which were linked to the clinic the same day. In Uganda and Kenya, an observational study of a combination approach of community-based testing followed by home-based HIV testing for community members not participating in the campaign tested 86,421 (88\%) of adolescents. ${ }^{48}$ The authors reported that 1,843 (2.1\%) individuals were newly diagnosed with HIV; however, they did not report on linkage to care.

\section{Discussion}

In this systematic review of HIV testing interventions among adolescents in high- versus low-/middle-income settings, we found 36 studies including 13 RCTs; yet only six studies discussed linkage to care. The primary purpose of screening for any disease is early diagnosis, so that diagnosed individuals can be promptly treated; this is true for HIV testing. Therefore, it is important that interventions to increase HIV testing not only address barriers to HIV testing but also include methods to effectively link newly diagnosed individuals to care.

Interventions that use technology and mobile health can address psychological barriers such as perceived risk, stigma, disclosure, and fear of rejection to increase HIV testing in adolescents. In the US, there were two RCTs and one pre-post evaluation that evaluated interventions using mobile health and technology to target key populations that significantly increased HIV testing among adolescents. ${ }^{37-39,64}$ In low- and middle-income countries, two RCTs and one retrospective observational study found that text messaging interventions targeting high-risk key populations significantly increased HIV testing among adolescents. ${ }^{49,51,61}$ In most settings, adolescents and young adults found text messaging and mobile health technology interventions acceptable and feasible. ${ }^{35-39,65-68}$ However, these interventions did not address structural barriers to HIV testing and none of the nine studies reported the numbers of new HIV diagnoses or linkage to care. Linking newly HIV diagnosed individuals is critical to improving the continuum of care among adolescents living with $\mathrm{HIV}^{7,8}$

Non-traditional HIV testing venues and oral self-testing can overcome structural barriers such as inconvenience, insurance, and parental consent to improve HIV testing among adolescents. ${ }^{69}$ In the US, one RCT and three observational studies found high levels of acceptability, but they offered limited data on linkage to care, which is particularly important for alternative venue testing. ${ }^{31-34,69}$ Oral self-testing was an acceptable HIV testing method among adolescents and could be a method employed to expand HIV testing programs; however, there are limited data on linkage to care after self-testing among adolescents. ${ }^{31,58}$ Within traditional health care venues, opt-out testing appears to improve HIV testing among adolescents compared to opt-in testing and may increase HIV testing over provider-initiated counseling and testing in high-prevalence areas. ${ }^{33,70,71}$ In low- and middle-income countries, door-to-door and mobile HIV testing was found to be feasible, acceptable, and led to large numbers of adolescents obtaining HIV testing; however, data on linkage to care is absent in those studies. ${ }^{43-45}$ In Malawi, door-to-door contact tracing of children born to HIV-infected mothers was a high yield method for detecting perinatal HIV in children and younger adolescents and could be expanded to other high HIV prevalence countries. ${ }^{57}$ Providing flexible, alternative strategies outside of traditional health care settings appears to be an acceptable, feasible, and effective method of increasing HIV testing among adolescents in the US and low- and middle-income countries. In lowand middle-income countries, alternative testing sites such as home self-testing, in-home door-to-door testing, testing campaigns, and pharmacy-based testing appear 
to be acceptable and feasible alternatives for HIV testing among adolescents; however, little is known about linkage to care after new HIV diagnosis in alternative venues. Of the eleven interventions involving alternative venue HIV testing, only two evaluated linkage to care, limiting the generalizability of these approaches. ${ }^{32,57}$

Community testing events and mobilization have the potential to overcome structural and psychosocial barriers by easing access, making testing normative, and providing social support; therefore, they have the ability to test large numbers of individuals and can be used to target high-risk, key populations. ${ }^{40,41,46,48,52,57,63}$ The only RCT in this category did not find efficacy in increasing HIV testing. ${ }^{47}$ However, six observational studies reported high levels of HIV testing in community interventions. In addition, two interventions reported successful linkage to care after HIV testing, making this an important component for future HIV testing modalities for adolescents. ${ }^{41,57,63}$

Other HIV testing interventions had mixed results and lower quality evidence for increasing HIV testing among adolescents. Interventions that involved behavioral change or education in the US were labor and resource intensive and showed variable results. ${ }^{29,30}$ These interventions appeared to be more effective in low- and middle-income countries compared to the US; however, none of these studies discussed the number of newly diagnosed HIV infections nor the number linked to care. Offering incentives for HIV testing among adolescents can address motivation for HIV testing but does not overcome many structural or psychosocial barriers to HIV testing, and sustainability may be challenging. ${ }^{53,54,62}$ In addition, there is limited data on the effectiveness of incentives on linkage to care after HIV testing. The specific use of youth-friendly testing facilities can address some structural and psychosocial barriers to HIV testing; however, these interventions did not have statistically superior effects compared to traditional testing sites..$^{59,60}$

Though critical to informing the implementation and scale-up of effective interventions, none of the studies reported resource utilization or costs related to HIV testing or the intervention. With resource utilization and cost data, health policy models can project the long-term impact of interventions beyond the time-horizon of traditional studies. This type of analysis is particularly important when considering testing interventions among youth, in whom the effects of HIV infection and treatment may not manifest for years or decades. ${ }^{5}$ Few studies have reported on the cost-effectiveness of adolescent-specific prevention or testing interventions. ${ }^{72-76}$ Such information is invaluable for policymakers to under- stand optimally deploying combinations of universal and targeted testing in specific settings and warrants more study moving forward. ${ }^{77}$

Current studies are exploring alternative methods and venues to improve HIV testing and linkage to care among high-risk adolescents. ${ }^{78}$ Mpower is an ongoing communitylevel intervention in the targeting young MSM using peer educators to engage high-risk youth to increase HIV testing. ${ }^{79}$ Other investigators are exploring the use of oral, self-testing with video counseling for transgender youth in the US. ${ }^{80}$ In Kenya, a large-scale study is evaluating alternative testing venues (community versus home) and testing modalities such as oral self-testing, home testing, mobile testing, or facility-based testing. ${ }^{81}$ Results of these studies may add valuable information for the development of multicomponent interventions to increase HIV testing among adolescents.

Future research should also focus on expanding the geographic reach of interventions for HIV testing among adolescents and young adults. In particular, this review did not identify any recently published interventions to increase HIV testing in Latin America or in high-income countries other than the US. Although the majority of HIV infections among adolescents occur in sub-Saharan Africa, HIV affects adolescents globally. It is important that effective interventions are identified that address culture-specific barriers and target local at-risk populations. ${ }^{3}$

\section{Conclusion}

To diagnose more HIV infections among adolescents, it is important to target high-risk populations, minimize barriers to HIV testing, and make testing easier and more widely available. One intervention is unlikely to address all of the barriers to HIV testing among adolescents and would be unlikely to succeed across all settings. Therefore, future interventions should utilize multiple components and expand on the successful use of mobile health technology, alternate venue testing, and community mobilization while stressing the importance of linkage to care. High-quality RCTs are needed to identify optimal combinations of interventions that increase HIV testing among adolescents while focusing on diagnosing new HIV infections and providing linkage to care.

\section{Author contributions}

All authors contributed to data analysis, drafting or revising the article, gave final approval of the version to be published, and agree to be accountable for all aspects of the work. 


\section{Disclosure}

$\mathrm{BCZ}$ received funding from the National Institutes of Health/ National Institute of Mental Health (No. K23MH114771) for his role as principal investigator. JEH received funding from the National Institutes of Health/National Institute of Mental Health (No. K24MH114732) for her role as principal investigator. The authors report no other conflicts of interest in this work.

\section{References}

1. Joint United Nations Programme on HIV/AIDS. Ambitious treatment targets: writing the final chapter of the AIDS epidemic. UNAIDS Geneva. 2015.

2. United Nations Children's Fund. Towards an AIDS-free Generation Children and AIDS. New York, NY: UNICEF; 2013.

3. Idele P, Gillespie A, Porth T, et al. Epidemiology of HIV and AIDS among adolescents: current status, inequities, and data gaps. J Acquir Immune Defic Syndr. 2014;66(Suppl 2):S144-153.

4. Centers for Disease Control and Prevention (CDC). HIV and Youth 2018. Available from: https:/www.cdc.gov/hiv/group/age/youth/.

5. Panel on Antiretroviral Guidelines for Adults and Adolescents. Guidelines for the use of antiretroviral agents in adults and adolescents living with HIV. Services Department of Health and Human Services, Department of Health and Human Services; 2018.

6. World Health Organization. Guideline on When to Start Antiretroviral Therapy and on Pre-exposure Prophylaxis for HIV. Geneva, Switzerland: World Health Organization; 2015.

7. Zanoni BC,Archary M, Buchan S, Katz IT, Haberer JE. Systematic review and meta-analysis of the adolescent and young adult HIV continuum of care in South Africa: the cresting wave. BMJ Global Health. 2016;1(3):e000004.

8. Zanoni BC, Mayer KH. The adolescent and young adult HIV cascade of care in the United States: exaggerated health disparities. AIDS Patient Care STDS. 2014;28(3):128-135.

9. de Wit JB, Adam PC. To test or not to test: psychosocial barriers to HIV testing in high-income countries. HIV Med. 2008;9(Suppl 2):20-22.

10. Peralta L, Deeds BG, Hipszer S, Ghalib K. Barriers and facilitators to adolescent HIV testing. AIDS Patient Care STDS. 2007;21(6):400-408.

11. Sam-Agudu NA, Folayan MO, Ezeanolue EE. Seeking wider access to HIV testing for adolescents in sub-Saharan Africa. Pediatr Res. 2016;79(6):838-845.

12. Li H, Wei C, Tucker J, et al. Barriers and facilitators of linkage to HIV care among HIV-infected young Chinese men who have sex with men: a qualitative study. BMC Health Serv Res. 2017;17(1):214.

13. Logie CH, Newman PA, Weaver J, Roungkraphon S, Tepjan S. HIVRelated stigma and HIV prevention uptake among young men who have sex with men and transgender women in Thailand. AIDS Patient Care STDS. 2016;30(2):92-100.

14. Mwangi RW, Ngure P, Thiga M, Ngure J. Factors influencing the utilization of Voluntary Counselling and Testing services among university students in Kenya. Glob J Health Sci. 2014;6(4):84-93.

15. Pharr JR, Lough NL, Ezeanolue EE. Barriers to HIV testing among young men who have sex with men (MSM): experiences from Clark County, Nevada. Glob J Health Sci. 2015;8(7): 9-17.

16. Solorio R, Norton-Shelpuk P, Forehand M, et al. Tu Amigo Pepe: evaluation of a multi-media marketing campaign that targets young latino immigrant MSM with HIV testing messages. AIDS Behav. 2016;20(9):1973-1988.

17. Strauss M, Rhodes B, George G. A qualitative analysis of the barriers and facilitators of HIV counselling and testing perceived by adolescents in South Africa. BMC Health Serv Res. 2015;15:250.
18. Catania JA, Dolcini MM, Harper GW, et al. Bridging barriers to clinicbased HIV testing with new technology: translating self-implemented testing for African American youth. Transl Behav Med. 2015;5(4):372-383.

19. Doll M, Fortenberry JD, Roseland D, Mcauliff K, Wilson CM, Boyer CB. Linking HIV-negative youth to prevention services in 12 U.S. cities: barriers and facilitators to implementing the HIV prevention continuum. J Adolesc Health. 2018;62(4):424-433.

20. Hyden C, Allegrante JP, Cohall AT. HIV testing sites' communication about adolescent confidentiality: potential barriers and facilitators to testing. Health Promot Pract. 2014;15(2):173-180.

21. Jennings L, Mathai M, Linnemayr S, et al. Economic context and HIV vulnerability in adolescents and young adults living in urban slums in Kenya: a qualitative analysis based on scarcity theory. AIDS Behav. 2017;21(9):2784-2798.

22. Wong VJ, Murray KR, Phelps BR, Vermund SH, Mccarraher DR. Adolescents, young people, and the 90-90-90 goals: a call to improve HIV testing and linkage to treatment. AIDS. 2017;31(Suppl 3): S191-S4.

23. Arnold EA, Rebchook GM, Kegeles SM. 'Triply cursed': racism, homophobia and HIV-related stigma are barriers to regular HIV testing, treatment adherence and disclosure among young Black gay men. Cult Health Sex. 2014;16(6):710-722.

24. Gao TY, Howe CJ, Zullo AR, Marshall BDL. Risk factors for self-report of not receiving an HIV test among adolescents in NYC with a history of sexual intercourse, 2013 YRBS. Vulnerable Child Youth Stud. 2017;12(4):277-291.

25. Helleringer S. Understanding the adolescent gap in HIV testing among clients of antenatal care services in West and Central African Countries. AIDS Behav. 2017;21(9):2760-2773.

26. Moher D, Liberati A, Tetzlaff J, Altman DG, Group PPRISMA Group. Preferred reporting items for systematic reviews and meta-analyses: the PRISMA statement. PLoS Med. 2009;6(7):e1000097.

27. Liberati A, Altman DG, Tetzlaff J, et al. The PRISMA statement for reporting systematic reviews and meta-analyses of studies that evaluate health care interventions: explanation and elaboration. PLoS Med. 2009;6(7):e1000100.

28. Guyatt GH, Oxman AD, Vist G, et al. GRADE guidelines: 4. Rating the quality of evidence - study limitations (risk of bias). J Clin Epidemiol. $2011 ; 64(4): 407-415$.

29. Letourneau EJ, Mccart MR, Sheidow AJ, Mauro PM. First evaluation of a contingency management intervention addressing adolescent substance use and sexual risk behaviors: risk reduction therapy for adolescents. J Subst Abuse Treat. 2017;72:56-65.

30. Donenberg GR, Emerson E, Mackesy-Amiti ME, Udell W. HIV-risk reduction with juvenile offenders on probation. J Child Fam Stud. 2015;24(6):1672-1684.

31. Merchant RC, Clark MA, Liu T, et al. Comparison of home-based oral fluid rapid HIV self-testing versus mail-in blood sample collection or medical/community HIV testing by young adult black, Hispanic, and white MSM: results from a randomized trial. AIDS Behav. 2018;22(1):337-346.

32. Holliday RC, Zellner T, Francis C, Braithwaite RL, Mcgregor B, Bonhomme J. Campus and community HIV and addiction prevention (CCHAP): an HIV testing and prevention model to reach young African American adults. J Health Care Poor Underserved. 2017;28(2S): 69-80.

33. Buzi RS, Madanay FL, Smith PB. Integrating routine HIV testing into family planning clinics that treat adolescents and young adults. Public Health Rep. 2016;131(Suppl 1):130-138.

34. Miller RL, Boyer CB, Chiaramonte D, et al. Evaluating testing strategies for identifying youths with HIV infection and linking youths to biomedical and other prevention services. JAMA Pediatr. 2017;171(6): $532-537$.

35. Aronson ID, Cleland CM, Perlman DC, et al. Mobile screening to identify and follow-up with high risk, HIV negative youth. J Mob Technol Med. 2016;5(1):9-18. 
36. Bauermeister JA, Pingel ES, Jadwin-Cakmak L, et al. Acceptability and preliminary efficacy of a tailored online HIV/STI testing intervention for young men who have sex with men: the Get Connected! program. AIDS Behav. 2015;19(10):1860-1874.

37. Dowshen N, Lee S, Matty Lehman B, Castillo M, Mollen C. IknowUshould2: Feasibility of a Youth-Driven Social Media Campaign to Promote STI and HIV Testing Among Adolescents in Philadelphia. AIDS Behav. 2015;19(Suppl 2):106-111.

38. Ybarra ML, Prescott TL, Phillips GL. 2nd, Bull SS, Parsons JT, Mustanski B. Pilot RCT Results of an mHealth HIV Prevention Program for Sexual Minority Male Adolescents. Pediatrics. 2017;140(1).

39. Washington TA, Applewhite S. Using social media as a platform to direct young Black men who have sex with men to an intervention to increase HIV testing. In: ; AIDS 2016: 21st International AIDS Conference; 2016; Durban, South Africa.

40. Shelley G, Williams W, Uhl G, et al. An Evaluation of Mpowerment on Individual-Level HIV Risk Behavior, Testing, and Psychosocial Factors Among Young MSM of Color: The Monitoring and Evaluation of MP (MEM) Project. AIDS Educ Prev. 2017;29(1):24-37.

41. Camacho-Gonzalez AF, Gillespie SE, Thomas-Seaton L, et al. The Metropolitan Atlanta community adolescent rapid testing initiative study: closing the gaps in HIV care among youth in Atlanta, Georgia, USA. AIDS. 2017;31(Suppl 3):S267-S75.

42. Pettifor A, Kahn K, Kimaru L, Mayakayaka Z. HIV Self-testing Increases Testing in Young South African Women: Results of an RCT. In: Conference on Retroviruses and Opportunistic Infections (CROI); 2018; Boston, MA.

43. Fatti G, Manjezi N, Shaikh N, Mothibi E, Oyebanji O, Grimwood A. An innovative combination strategy to enhance HIV testing amongst adolescents in South Africa. In: AIDS 2016: 21st International AIDS Conference; 2016; Durban, South Africa.

44. Rousseau-Jemwa E, Smith P, Zakariya D, Bekker LG. Communitybased HIV testing for adolescent sexual and reproductive health: results from a mobile clinic initiative. In: AIDS 2016: 21st International AIDS Conference; 2016; Durban, South Africa.

45. Shanaube K, Schaap A, et alHPTN 071 (PopART) Study Team, et al. Community intervention improves knowledge of HIV status of adolescents in Zambia: findings from HPTN 071-PopART for youth study. AIDS. 2017;31(Suppl 3):S221-S32.

46. Hershow R, Gannett K, Merrill J, et al. Using soccer to build confidence and increase HCT uptake among adolescent girls: A mixed-methods study of an HIV prevention programme in South Africa. Sport Soc. 2015;18(8):1009-1022.

47. Rotheram-Borus MJ, Tomlinson M, Durkin A, Baird K, Decelles J, Swendeman D. Feasibility of Using Soccer and Job Training to Prevent Drug Abuse and HIV. AIDS Behav. 2016;20(9):1841-1850.

48. Kadede K, Ruel T, et alSEARCH team, et al. Increased adolescent HIV testing with a hybrid mobile strategy in Uganda and Kenya. AIDS. 2016;30(14):2221-2226.

49. Njuguna N, Ngure K, Mugo N, et al. The Effect of Human Immunodeficiency Virus Prevention and Reproductive Health Text Messages on Human Immunodeficiency Virus Testing Among Young Women in Rural Kenya: A Pilot Study. Sex Transm Dis. 2016;43(6):353-359.

50. Mugo PM, Prins HA, Wahome EW, et al. Engaging young adult clients of community pharmacies for HIV screening in Coastal Kenya: a crosssectional study. Sex Transm Infect. 2015;91(4):257-259.

51. Mugo PM, Wahome EW, Gichuru EN, et al. Effect of Text Message, Phone Call, and In-Person Appointment Reminders on Uptake of Repeat HIV Testing among Outpatients Screened for Acute HIV Infection in Kenya: A Randomized Controlled Trial. PLoS One. 2016;11(4): e0153612.

52. Hossain S, Sultana N, Hossain T, Zieman B, Roy S, Pilgrim N, et al. Does peer outreach increase HIV testing self-efficacy and uptake? Evaluation of the Link Up program in Bangladesh brothels. In: ; AIDS 2016: 21st International AIDS Conference; 2016; Durban, South Africa.

53. Oyewale TO, Ahmed S, Ahmed F, et al. The use of vouchers in HIV prevention, referral treatment, and care for young MSM and young transgender people in Dhaka, Bangladesh: experience from 'HIM' initiative. Curr Opin HIV AIDS. 2016;11(Suppl 1):S37-S45.
54. Chapman J, Ngunga M, Chariyeva Z, Simbaya J, Kamwanga J, Kaira W. Improved HIV testing uptake, food security and reduced violence among orphans and vulnerable children in Zambia: the impact of using baseline data to define program scope. In: IAS 2015 8th IAS Conference on HIV Pathogenesis, Treatment, and Prevention; 2015; Vancouver, Canadad.

55. Firestone R, Moorsmith R, James S, et al. Intensive Group Learning and On-Site Services to Improve Sexual and Reproductive Health Among Young Adults in Liberia: A Randomized Evaluation of HealthyActions. Glob Health Sci Pract. 2016;4(3):435-451.

56. Jani N, Vu L, Kay L, Habtamu K, Kalibala S. Reducing HIV-related risk and mental health problems through a client-centred psychosocial intervention for vulnerable adolescents in Addis Ababa, Ethiopia. J Int AIDS Soc. 2016;19(5 Suppl 4):20832.

57. Ahmed S, Sabelli RA, Simon K, et al. Index case finding facilitates identification and linkage to care of children and young persons living with HIV/AIDS in Malawi. Trop Med Int Health. 2017;22(8): 1021-1029.

58. Hector J, Davies MA, Dekker-Boersema J, et al. Acceptability and performance of a directly assisted oral HIV self-testing intervention in adolescents in rural Mozambique. PLoS One. 2018;13(4):e0195391.

59. Aung PP, Ryan C, Bajracharya A, et al. Effectiveness of an Integrated Community- and Clinic-Based Intervention on HIV Testing, HIV Knowledge, and Sexual Risk Behavior of Young Men Who Have Sex With Men in Myanmar. J Adolesc Health. 2017;60(2S2):S45-S53.

60. Aninanya GA, Debpuur CY, Awine T, Williams JE, Hodgson A, Howard $\mathrm{N}$. Effects of an adolescent sexual and reproductive health intervention on health service usage by young people in northern Ghana: a community-randomised trial. PLoS One. 2015;10(4):e0125267.

61. Nevendorff L, Mukaromah Y, Nurhalinah A, Perdana S, Widodo W, Tasya IA, et al. Reaching unreachable population: multi-collaboration framework to improve young key population access towards HIV-related services in demonstration site of Bandung, Indonesia. In: AIDS 2016: 21st International AIDS Conference; 2016; Durban, South Africa.

62. Dakshina S, Bandason T, Dauya E, Kranzer K, Mchugh G, Munyati S, et al. The impact of incentives on uptake of HIV testing among adolescents in a high HIV prevalence setting. In: AIDS 2016: 21st International AIDS Conference; 2016; Durban, South Africa.

63. Reif LK, Rivera V, Louis B, et al. Community-Based HIV and Health Testing for High-Risk Adolescents and Youth. AIDS Patient Care STDS. 2016;30(8):371-378.

64. Tso LS, Tang W, Li H, Yan HY, Tucker JD. Social media interventions to prevent HIV: A review of interventions and methodological considerations. Curr Opin Psychol. 2016;9:6-10.

65. Garett R, Smith J, Young SD. A Review of Social Media Technologies Across the Global HIV Care Continuum. Curr Opin Psychol. 2016;9:56-66.

66. Belzer ME, Kolmodin MacDonell K, et al. Adolescent Medicine Trials Network for HIV/AIDS Interventions, et al. Acceptability and Feasibility of a Cell Phone Support Intervention for Youth Living with HIV with Nonadherence to Antiretroviral Therapy. AIDS Patient Care STDS. 2015;29(6):338-345.

67. Cooper V, Clatworthy J, Whetham J, Consortium E. mHealth Interventions To Support Self-Management In HIV: A Systematic Review. Open AIDS J. 2017;11:119-132.

68. Hightow-Weidman LB, Muessig KE, Bauermeister J, Zhang C, Legrand S. Youth, Technology, and HIV: Recent Advances and Future Directions. Curr HIV/AIDS Rep. 2015;12(4):500-515.

69. Marano MR, Stein R, Williams WO, et al. HIV testing in nonhealthcare facilities among adolescent MSM. AIDS. 2017;31(Suppl 3):S261-S265.

70. Govindasamy D, Ferrand RA, Wilmore SM, et al. Uptake and yield of HIV testing and counselling among children and adolescents in subSaharan Africa: a systematic review. J Int AIDS Soc. 2015;18:20182.

71. Minniear TD, Gilmore B, Arnold SR, Flynn PM, Knapp KM, Gaur AH. Implementation of and barriers to routine HIV screening for adolescents. Pediatrics. 2009;124(4):1076-1084.

72. Pinkerton SD, Holtgrave DR, Jemmott JB. Economic evaluation of HIV risk reduction intervention in African-American male adolescents. $J$ Acquir Immune Defic Syndr. 2000;25(2):164-172. 
73. Tao G, Remafedi G. Economic evaluation of an HIV prevention intervention for gay and bisexual male adolescents. J Acquir Immune Defic Syndr Hum Retrovirol. 1998;17(1):83-90.

74. Neilan AM, Dunville R, Ocfemia MCB, et al. The Optimal Age for Screening Adolescents and Young Adults Without Identified Risk Factors for HIV. J Adolesc Health. 2018;62(1):22-28.

75. Kahn JG, Kegeles SM, Hays R, Beltzer N. Cost-effectiveness of the Mpowerment Project, a community-level intervention for young gay men. J Acquir Immune Defic Syndr. 2001;27(5):482-491.

76. Neilan AB, Freedberg AJ, Hosek KA, Landovitz SG, Wilson RJ, Walensky CM, Ciaranello, AL RP. Cost-effecteness of repeat screening in high-risk youth. In: Conference on Retroviruses and Opportunistic Infections; 2018; Boston, MAMarch.

77. Agwu AL, Quinn TC. Finding Youths at Risk for HIV Infection: Targeted Testing, Universal Testing, or Both? JAMA Pediatr. 2017;171(6):517-518.

78. Trials A.C; 2018. Available from: https://atnweb.org/atnweb/studies.

79. Fenkl EA, Jones SG, Oves JC. Panther Mpower: A Campus-Based HIV Intervention for Young Minority Men who Have Sex with Men. J Health Care Poor Underserved. 2017;28(2S):9-15.
80. Stephenson R, Metheny N, Sharma A, Sullivan S, Riley E. Providing Home-Based HIV Testing and Counseling for Transgender Youth (Project Moxie): Protocol for a Pilot Randomized Controlled Trial. JMIR Res Protoc. 2017;6(11):e237.

81. Inwani I, Chhun N, Agot K, et al. High-Yield HIV Testing, Facilitated Linkage to Care, and Prevention for Female Youth in Kenya (GIRLS Study): Implementation Science Protocol for a Priority Population. JMIR Res Protoc. 2017;6(12):e179.

82. Frye V, Wilton L, et alAll About Me Study Team, et al. "Just Because It's Out There, People Aren't Going to Use It.” HIV Self-Testing Among Young, Black MSM, and Transgender Women. AIDS Patient Care STDS. 2015;29(11):617-624.

83. Fisher CB, Fried AL, Macapagal K, Mustanski B. Patient-Provider Communication Barriers and Facilitators to HIV and STI Preventive Services for Adolescent MSM. AIDS Behav. 2018.

84. Bhoobun S, Jetty A, Koroma MA, et al. Facilitators and barriers related to voluntary counseling and testing for HIV among young adults in Bo, Sierra Leone. J Community Health. 2014;39(3):514-520.
Adolescent Health, Medicine and Therapeutics

\section{Publish your work in this journal}

Adolescent Health, Medicine and Therapeutics is an international, peer-reviewed, open access journal focusing on health, pathology, and treatment issues specific to the adolescent age group. All aspects of health maintenance, preventative measures and disease treatment interventions are addressed within the journal and practitioners from all disciplines are

\section{Dovepress}

invited to submit their work as well as healthcare researchers and patient support groups. This journal is included in PubMed. The manuscript management system is completely online and includes a very quick and fair peer-review system. Visit http://www.dovepress.com/testimonials. php to read real quotes from published authors. 